\title{
Crise pós-2008 nas cidades portuguesas da NUT III Oeste: desemprego e exclusão social
}

\author{
Post-2008 crisis in the Portuguese cities \\ of NUT III Oeste: unemployment and social exclusion
}

Carlos Gonçalves

\begin{abstract}
Resumo
Neste artigo, avaliam-se os impactos da crise pós-2008 no desemprego, na acessibilidade a fontes de rendimento e a bens essenciais e nas situações de pobreza e de exclusão vivenciadas pelas famílias residentes nas cidades da NUT III Oeste ${ }^{1}$ (Alcobaça, Caldas da Rainha, Peniche e Torres Vedras). Os resultados obtidos baseiam-se em trabalho de campo (inquiriram-se 387 famílias, recolhendo-se informação referente a 1.028 indivíduos), realizado entre os dias 4 de abril e 6 de maio de 2014. 0 quadro geral de resultados a que chegamos quantifica e qualifica a degradação do acesso ao emprego e, por conseguinte, a fontes de rendimentos por parte das famílias, expondo múltiplas dimensões da exclusão social que essas comunidades conheceram no decurso dos 6 anos analisados.
\end{abstract}

Palavras-chave: crise pós-2008; mercado de trabalho; desemprego; rendimento familiar; exclusão social.

\begin{abstract}
In this paper, we evaluate the impact of the post-2008 crisis on unemployment, accessibility to sources of income and essential goods, and on situations of poverty and exclusion experienced by families living in the cities of NUT III Oeste ${ }^{2}$ (Alcobaça, Caldas da Rainha, Peniche and Torres Vedras). The results are based on a fieldwork (387 households were inquired and the collected information refer to 1,028 individuals) that was conducted from April 4 to May 6, 2014. Overall, the results we attained quantify and qualify the decline of the access to employment and, as a consequence, to sources of income by the households, exposing multiple dimensions of the social exclusion that these communities experienced in the six years that were analyzed (between 2008 and 2014).
\end{abstract}

Keywords: Post-2008 crisis; labor market; unemployment; household income; social exclusion. 


\section{Introdução}

A extensão e a rapidez de progressão da crise que eclodiu no início do segundo semestre do ano de 2008 transformaram o colapso do sistema de crédito à habitação (subprime) dos Estados Unidos da América (EUA) e dos correlativos mecanismos de seguros, numa crise financeira e econômica de dimensão global. Com as principais instituições financeiras dos EUA em falência, rapidamente se propagaram os efeitos para o sistema financeiro internacional que, por sua vez, globalizou os mecanismos de recessão econômica (Kotz, 2009). No contexto europeu, os efeitos da crise pós-2008 só são comparáveis com os da Grande Depressão dos anos 1930 (Ecotrust, 2012; Urbact, 2010; European Commission, 2011 e Fujita, 2013). Isso quer dizer que o contexto de crise iniciado em 2008 não tem precedentes na história econômica europeia do período pós-guerra (European Commission Directorate-General for Economic and Financial Affairs, 2009).

Essa singularidade, no que diz respeito à rapidez do efeito de contágio e à extensão dos impactos, contrasta com a proximidade dos processos que estão na sua origem em face de outros episódios de crise experienciados no passado (como no Japão e nos países Nórdicos, no início dos anos 1990, e na crise Asiática do final dos anos 1990). Ou seja, todos são marcados pela existência de um período de forte expansão do crédito associado às falhas na avaliação do risco, pela profusão da liquidez na economia, pela procura e pelos preços mobilizados por dinâmicas especulativas e por "bolhas" geradas nos setores públicos. Um sistema econômico assente numa matriz financeiro-imobiliária sobreinflacionada vulnerabiliza as instituições, as empresas e as famílias que asseguram o seu rendimento na economia real, isto é: no mercado de produtos e serviços transacionáveis.

Na confluência de fatores desse gênero, qualquer gatilho (nesse caso, como se referiu acima, foi o desmoronamento do mercado subprime nos EUA) gera ondas que desagregam os sistemas financeiro, econômico e social (European Commission Directorate-General for Economic and Financial Affairs, 2009). 0 relatório da Comissão Europeia, anteriormente citado, estimou que a queda do Produto Interno Bruto (PIB) comunitário seria de $4 \%$ ao ano, de 2009, representando a maior contração econômica da sua história. A profundidade desse processo de crise, iniciado em 2008, cuja sequência de aprofundamento se encontra resumida, por exemplo, em Tosun, Wetzel e Zapryanova (2014, p. 197), gerou diversas interpretações, que se apresentam, de modo resumido, a seguir.

Esse processo de crise pode ser enquadrado num movimento mais amplo de disfunções sistêmicas financeiras e dos setores públicos, associadas ao aprofundamento de uma linha especifica do capitalismo, dito neoliberal. Essa interpretação aproxima a progressão desse tipo de capitalismo (de cariz neoliberal) à inevitabilidade da crise como mecanismo para o seu aprofundamento. Nessa linha interpretativa, a crise não representa um fenômeno esporádico, pelo contrário, trata-se de uma recorrência sistêmica ${ }^{3}$ que só será resolvida se se introduzirem alterações na natureza do próprio modelo socioeconômico (Kotz, 2009). Esse sentido integrado faz-se acompanhar da consciência da necessidade de políticas capazes de reformar os mecanismos de regulação 
dos mercados financeiros, desligando-os da lógica prevalecente emanada do consenso de Washington (Silvey, 2010).

Na União Europeia, entre a necessidade identificada de rever os mecanismos de regulação do sistema financeiro, a cadeia de impossibilidades que se foram firmando, as soluções de austeridade implementadas em Estados-membros mais vulneráveis (Irlanda, Grécia, Espanha e Portugal, aos quais foi imposto, numa primeira fase, que recorressem aos seus orçamentos para amortecer os efeitos das falências das instituições financeiras), emergem episódios que somam uma dimensão política às restantes frentes da crise (Tosun, Wetzel e Zapryanova, 2014). Decorre do que se disse anteriormente: uma leitura multidimensional (financeira, bancária, de dívida pública, macroeconômica) de interligações que potencializam os efeitos da crise.

Abrindo o espetro de análise, Homer-Dixon et al. (2015) defendem que a bitola para a interpretação das crises será marcada, no futuro, pela arquitetura dos acontecimentos de 2008-2009. Os autores analisam a matriz intersistêmica (de cariz globalizante) e propõem o reconhecimento de um estado de crise que designam como synchronous failure, assinalando o quadro sincronizado de colapsos. Na definição de sistema, agrega-se um conjunto de entidades por via de mecanismos que conferem unicidade e identidade perdurável por longos períodos de tempo. No caso dos sistemas socioecológicos abordados pelos autores, conjugam-se recursos, organismos naturais, comunidades em diferentes estados de desenvolvimento, organizações, instituições e tecnologias. Num cenário de crise, as ligações entre todos esses elementos são perturbadas de modo articulado por eventos desencadeados num curto período de tempo, prejudicando duradouramente a qualidade de vida de boa parte da população (ibid., 2015). A cadeia de disfunções ecológicas, financeiras, energéticas, econômicas, políticas ou tecnológicas que amplifica os efeitos da crise não tem sequência preestabelecida é antecipada por acontecimentos aparentemente irrelevantes, é detonada repentinamente e ganha ressonância com a sincronização de falhas nos diferentes subsistemas, criando dinâmicas de degradação e retrocesso social.

0 relatório da Comissão Europeia de 2009 Economic crisis in Europe: causes, consequences and responses (European Commission Directorate-General for Economic and Financial Affairs, 2009) sinaliza os impactos esperados no mercado de trabalho: mecanismos de flexibilização implementados, sobretudo, nos estados mais vulneráveis, com alterações nos horários, encerramentos temporários, contração dos salários e facilidades de despedimento, degradariam o mercado de trabalho. A par desses processos, a taxa de desemprego subiu 2,1\% na União Europeia, entre 2008 e julho de 2009. Nesse período, 0 relatório Employment in Europe 2009 registava o anúncio da destruição de 100.000 empregos entre os meses de dezembro de 2008 e janeiro de 2009. Entre março de 2008 e agosto de 2009, assistiu-se a uma retração do emprego em quase todos os setores, sendo os mais afetados: 0 automobilístico $(-11,2 \%)$, a administração pública $(-8,5 \%)$, o comércio $(-7,7 \%)$, os correios e telecomunicações $(-7,5)$ e os serviços de intermediação financeira $(-7,3 \%)$, (European Commission, Directorate-General for Employment, 2009, p. 31). 
0 relatório Employment and social developments in Europe 2015 (Commission European, Directorate-Gerneral for Employment, 2015) mostra a evolução no emprego, cuja recuperação começou em 2013, mantendo-se em cerca de 0,9\%, em 2015. Apesar da evolução observada em 2015, a União Europeia ainda tinha menos 2,7 milhões de empregados ante o total registado no segundo quadrimestre de 2008. As condições sociais inerentes ao emprego mostram sinais de degradação na medida em que os contratos permanentes foram os que sofreram um declínio maior. Mesmo quando se registrou uma recuperação lenta do emprego, a partir de 2013, o que se viu foi o aumento dos contratos temporários. No final de 2015 o número de pessoas que trabalhavam em tempo integral ainda era 4,2\% inferior ao valor de 2008. Em contraponto o emprego a tempo parcial cresceu 9,8\% (Commission, European, Directorate-General for Employment, 2015).

Desde 2008, países como Irlanda, Grécia, Espanha e Portugal tiveram uma contração nos custos unitários do trabalho e, apesar de se poder somar os apoios sociais e o rendimento do trabalho para formar o rendimento familiar, o certo é que o relatório a que temos referido conclui que o rendimento disponível das famílias ainda é inferior ao máximo verificado em 2009, assistindo-se pós-2008 à progressão da população que vive em famílias marcadas por situações de carência de emprego (People living in low work intensity households). Essa situação de debilidade familiar passou de $9 \%$, em 2008, para cerca 11\%, em 2014. Portugal coloca-se entre os estados em que a pobreza e a exclusão social aumentaram entre 2008 e 2014 , aumento que atingiu cerca de $29 \%$ da população. Esse quadro de crise marcado por contração do emprego e retração das condições sociais manifestou-se com grande severidade no sul da Europa, aprofundando as condições de desigualdade que já existiam no período pré-crise (Hadjimichalis, 2011), fragilizando a coesão entre estados e também entre regiões (Cuadrado-Roura, Martin e Rodríguez-Pose, 2016; Marelli, Patuelli e Signorelli, 2012).

Nos sistemas capitalistas, os mecanismos de exclusão apresentam-se de diferentes formas, todavia é através dos bloqueios no acesso ao mercado de trabalho que os efeitos descem no nível dos indivíduos, das famílias e das comunidades. A exclusão social centra-se primeiramente em aspetos relacionais, bloqueados pela não participação no mercado de trabalho e nos mecanismos de decisão, pelo isolamento social e pela incapacidade de exercício dos direitos de cidadania. Sendo mais abrangente, o conceito foca-se na carência de rendimentos que afasta os indivíduos, as suas famílias e as comunidades com maior risco de exclusão do acesso a serviços e bens essenciais, tais como: saúde, educação e habitação. Trata-se de um processo dinâmico de marginalização de grupos sociais no contexto das regiões a que pertencem (Atkinson e Davudi, 2000).

A multidimensionalidade do conceito de exclusão social dialoga com a noção de pobreza vista como um resultado da escassez de rendimentos que afasta os indivíduos de participação nos círculos em que se materializa a vida quotidiana da comunidade. A conjugação dinâmica e complexa desses estratos de marginalização compõe um "vocabulário de desvantagens", misturando bloqueios no acesso a recursos com desintegração das instituições sociais fundamentais para que os indivíduos 
tenham uma vida digna e possam evoluir (O'Brien e Penna, 2008). É comum falar de risco de exclusão para tipificar processos que conduzem grupos de indivíduos, comunidades ou territórios a situações que os afastam desses círculos de participação na vida diária (Madanipour, Shucksmith e Talbot, 2015).

Cutter, Boruff e Shirley (2003) propõem que se observe o conceito de vulnerabilidade a partir de três componentes. É possível identificar as condições que tornam as comunidades e os lugares mais vulneráveis ("o que as expõe a..."), tomar a vulnerabilidade como uma condição social, traduzível para uma medida de resistência a crises ("o que as prepara para...") e, no terceiro lado, em que se exibe o resultado dos outros dois: condições de exposição a riscos (vulnerabilidade) e de resiliência de lugares ou regiões específicas; isso é, a sua dimensão territorial. Por causa das dificuldades que se colocam à sua medição, a vulnerabilidade social é recorrentemente negligenciada, mesmo nos relatórios que se destinam a apurar as perdas que uma determinada crise provocou. Quando muito, referem-se a características individuais, tais como: idade, raça, escalão de rendimentos, tipo de emprego ou padrão de distribuição dos lugares de residência (ibid.).

No conceito de vulnerabilidade social, incorpora-se o risco, que algumas famílias apresentam, de resvalar para situações de pobreza ou de prolongá-las, internalizando-as como uma fatalidade, uma armadilha, uma situação crônica. Porém, o foco é desviado para a vulnerabilidade dos lugares, admitindo que a própria pobreza é, por si só, fator de vulnerabilidade para uma região, vulnerabilidade esta entendida como função da geografia econômica que internaliza os determinantes sociopolíticos de uma dada região. Consideram-se elementos de fragilidade que podem decorrer da estrutura econômica, o perfil ambiental, a matriz institucional ou as estruturas de governação. É estreita a relação entre vulnerabilidade e rendimento per capita, porquanto, as estratégias que aumentam 0 rendimento das famílias, de um modo geral, reduzem a vulnerabilidade das comunidades (Naudé, McGillivray e Rossouw, 2009).

Nas últimas décadas, agudizou-se a recorrência de diferentes tipos de crises sobrepondo-se as de cariz ambiental com as de natureza econômica, financeira, social ou política. Esse quadro contribui para a emergência da vulnerabilidade e da percepção do risco associado à globalização e ao aprofundamento de políticas neoliberais na medida em que torna as comunidades mais permeáveis aos efeitos do que era usual ser denominado fatores externos (Eraydin, 2013), obrigando a renovações nas análises territoriais de forma a identificar, com mais rigor, as vulnerabilidades dos sistemas urbanos e quais as perspectivas de planeamento mais adequadas para as enquadrar. Enquanto a desregulação dos fluxos de produtos, capital e pessoas diminui o nível de proteção das economias locais aos efeitos externos, a volatilidade econômica global aumenta a vulnerabilidade dos sistemas urbanos.

A vulnerabilidade é uma das componentes analisadas nas abordagens à resiliência dos sistemas urbanos e das comunidades que os constituem (Seeliger e Turok, 2013) quando colocados perante necessidades abruptas de lidar com a mudança provocada por contextos de tensão, crise ou colapso combinando níveis de exposição, sensibilidade, impactos potenciais e capacidade adaptativa (Espon, 2013). 
Vulnerabilidade corresponde a diferentes níveis de exposição aos efeitos provocados por fenômenos de crise, mas também se pode traduzir na capacidade de antecipar danos, correspondendo a uma condição dinâmica que as comunidades manifestam (Miller et al., 2010).

Recorrendo ao conceito de vulnerabilidade (desenvolvido na ecologia política, na economia política e nas abordagens à redução de riscos), potencia-se a observação de grupos sociais específicos que são mais suscetíveis se serem afetados pelos efeitos de processos de crise (Seeliger e Turok, 2013). Ter condições para suportar os custos com alimentação, com habitação ou com os cuidados de saúde constituem necessidades básicas que se interligam diretamente com o acesso ao emprego. Todavia, ter um emprego, em muitos casos, não constitui uma resposta que afaste uma família do risco de pobreza, são necessários mecanismos complementares de inclusão social que garantam as necessidades básicas e os níveis mínimos de cidadania (Eurofound, 2016).

A análise das capacidades de lidar com os efeitos da crise, de medir os seus impactos e também (talvez, e sobretudo) em identificar os fatores que conferem resiliência evolutiva aos países, às regiões e às comunidades (por oposição aos processos de aprofundamento da exclusão social), constitui um enorme desafio para a Geografia, desde logo porque todos estes campos de estudo evidenciam padrões de distribuição territorial suscitadores de questões geográficas: "onde?", "por quê?", "quem?", "para quem?". Mas, sobretudo porque a recorrência dos episódios de crises (de origem ambiental, por via de fenômenos extremos, de disfunções econômica, política ou sociais) é cada vez maior, importa identificar e explicar as diferenças na distribuição dos impactos. Quais os territórios (que grupos, comunidades, regiões) que perdem com as crises? Quais os territórios (que grupos, comunidades, regiões) que ganham com as crises?

Na Europa as dimensões geográficas de condições de partida, de impactos e de capacidade de resposta, têm mobilizado o esforço de vários autores (Hadjimichalis, 2011; Raco e Street, 2012; Garretsen, McCann, Martin e Tyler, 2013; Cuadrado-Roura, Martin e Rodríguez-Pose, 2016; Fratesi e Rodríguez-Pose, 2016). Neste artigo, as relações que pretendemos relevar são as que exploram a ligação entre a crise pós-2008, as transformações no mercado de trabalho e os efeitos transpostos para as condições de vida das comunidades atentando à escala urbana/sistema urbano. Apesar de ser evidente o esforço de avaliação dos impactos da crise, no contexto da União Europeia, diferenciando-se os progressivos efeitos do abandono dos objetivos da coesão, são ainda escassas as investigações que se dedicam a observar os efeitos na escala urbana fazendo uso de instrumentos de observação direta (recorrendo a inquéritos à população) que permitam aprofundar, com detalhe, as alterações no mercado de trabalho e consequentes implicações sociais.

Neste artigo procuramos contribuir para a supressão dessa debilidade. Assim, para além desta introdução onde se procurou enquadrar a dimensão da crise pós-2008 dialogando com os conceitos de exclusão e vulnerabilidade social, apontando a sua especificidade europeia (do sul da Europa e de Portugal), nos pontos seguintes apresenta-se uma análise detalhada dos efeitos da crise no período que vai de 2008 a 2014, tomando como caso de estudo 
quatro cidades portuguesas que configuram o sistema urbano da NUT III Oeste (Nomenclatura das Unidades Territoriais para Fins Estatísticos). Os resultados deste estudo decorrem de informação recolhida em campo, desenvolvido entre 4 de abril e 6 de maio de 2014. Para além da apresentação resumida da metodologia, a análise divide-se em dois blocos. No primeiro bloco é analisada a vulnerabilidade das famílias no acesso a rendimentos e o aumento do desemprego. No segundo bloco aborda-se a vulnerabilidade das famílias no acesso a bens essenciais e o aprofundamento das situações de exclusão social. 0 artigo é rematado com um conjunto de considerações finais onde se destacam os principais impactos da crise pós-2008 apurados nas cidades tomadas como casos de estudo.

\section{Casos de estudo e metodologia do trabalho de campo}

Composta por 387 questionários validados, a amostra distribuiu-se do seguinte modo pelas quatro cidades ${ }^{4}$ consideradas neste estudo: 10,6\% realizados em Alcobaça, 40,8\% nas Caldas da Rainha, 21,7\% em Peniche e 26,9\% em Torres Vedras. A coerência entre essa representação e o peso demográfico de cada um dos centros urbanos foi assim respeitada, na medida em que o quantitativo de questionários aplicados em cada centro urbano reproduz a sua representação populacional. Essas entrevistas foram organizadas e aplicadas de modo a recolher informação sobre a amostra restrita (387 famílias) e sobre a amostra alargada
(1.028 pessoas pertencentes aos respectivas agregados familiares para as quais se coletou informação).

A amostra integra $44 \%$ de homens e $56 \%$ de mulheres. Decorrente da pulverização da amostra restrita pela generalidade dos grupos etários, reproduz-se a diversidade da população, tanto nos centros urbanos considerados individualmente, como no sistema urbano visto de modo agregado. Na maioria dos grupos etários internalizamos, na amostra alargada, representações entre 4 e 10\% de indivíduos. A amostra é composta por $21,2 \%$ de indivíduos com menos de 20 anos; $65,2 \%$ posicionados entre os 20 e os 64 ; e $13 \%$ com mais de 65 anos. Vinte e dois por cento apresentam níveis de escolaridade igual ou inferior à $4^{\mathrm{a}}$ classe ${ }^{5}$; $27,4 \%$ têm entre 5 e 9 anos de educação escolar; $27 \%$ dos entrevistados afirmam ter o ensino secundário completo; e 23\% referem que possuem formação superior.

Atentando à dimensão dos núcleos familiares, podemos constatar que $14 \%$ são constituídas por apenas um elemento; 35\% apresentam-se com dois; $27 \%$ com três; e 23\% são constituídas por mais de três elementos. Para tal, desagregamos a base de dados permitindo-nos identificar 26 tipos diferentes de núcleos familiares. Assim, registamos cerca de 3\% de agregados sem ascendentes ou mesmo sem parentesco entre os seus elementos; $14 \%$ de núcleos unipessoais; $15 \%$ que integram a tipologia de monoparentais; $23 \%$ de famílias que são constituídas por casais sem filhos; e 44,7\% por casais com filhos.

0 trabalho de campo foi desenvolvido entre 4 de abril e 6 de maio de 2014, distribuído pelos diferentes dias da semana, incluindo todos os finais de semana do período em 
causa, para, desse modo, atenuar a possível menor presença de famílias com indivíduos ativos nos locais onde se realizaram os questionários. Foram dois os critérios tomados em conta na seleção dos indivíduos a inquirir: o entrevistado tinha de ser residente nas respectivas cidades e tinha de ter idade superior a 18 anos. 0 primeiro critério serviu para isolar a informação em torno das famílias que residem nos respectivos centros urbanos. 0 segundo teve em vista aumentar a consistência da informação, uma vez que a estrutura do questionário pressupõe que o respondente forneça dados para a totalidade do agregado familiar. Tendo em conta a natureza das questões, exigiu-se um nível de consciência elevado sobre as diferentes áreas do quadro de vida das famílias, pelo que se entendeu que se deveriam considerar apenas respondentes maiores de idade.

0 processo de escolha obedeceu a dois critérios simples: 1) abordou-se sempre o primeiro transeunte com quem cruzássemos no local escolhido; 2) foram entrevistados, sem exceção, todos os que, cumprindo os pressupostos anteriores, dispuseram-se a colaborar com o estudo. Com algumas variações, tendo em conta os dias da semana e as cidades em causa, a taxa de rejeição foi reduzida, e a taxa de abandono das entrevistas foi praticamente nula, apartando-se, no final, apenas quatro registos incompletos.

As entrevistas foram aplicadas em áreas das cidades para as quais confluíssem todos os tipos de famílias, pelo que se privilegiaram os espaços centrais nos quais pudessem ser encontradas várias funções, nomeadamente comerciais: supermercados, lojas de rua e mercados. Trata-se de um sistema urbano marcado por um crescimento demográfico na ordem dos
$14 \%$, se tivermos em conta o intervalo temporal 1991/2011 (crescimentos de 8,7\% entre 1991 e 2001 e de $5 \%$ entre 2001 e 2011). No conjunto das 4 cidades, viviam, segundo o último registro censitário, 66.776 residentes. Nos 12 concelhos que integram a NUT III Oeste, residiam, em 2011, um pouco mais de 362.500 habitantes. A representação demográfica dos 4 concelhos onde se localizam os centros urbanos de maior relevo regional está muito próximo dos $60 \%$. Todavia, esses centros urbanos concentram apenas $18,4 \%$ da população da respetiva NUT. Tal fato é representativo de um sistema urbano com baixa capacidade de polarização demográfica.

Diferentes estruturas urbanas podem ser encontradas nas 4 cidades. Peniche apresenta uma matriz mais compacta refletida numa densidade demográfica de 2.133 residentes por $\mathrm{km}^{2}$. Caldas da Rainha segue-se nessa medida de concentração da população com um núcleo central mais consolidado, manifestando-se numa densidade de 1.607 residentes por $\mathrm{km}^{2}$. Torres Vedras e Alcobaça apresentam modelos com menor compactação, vertendo essa característica para densidades de 1.357 e 1.104 residentes por $\mathrm{km}^{2}$, respectivamente. As cidades médias em Portugal, em que se enquadram os casos de estudo, aumentaram a sua população ao longo das últimas décadas, tendo-se criado bairros residenciais que se articulam com a área central onde se mantém uma parte significativa das funções comerciais e dos serviços. Tratando-se de cidades com uma dimensão reduzida, desenvolvendo-se, com diferentes configurações, em torno de um raio entre 2 e $4 \mathrm{~km}$ da área central. Dessa forma, os espaços públicos centrais são ocupados por toda a população da cidade, compondo uma mistura de 
estratos etários e sociais. Para além da exposição a uma diversidade maior de famílias, por essa via incrementamos a aleatoriedade, que certamente seria menor se a opção privilegiasse áreas residenciais, estas mais facilmente segregadoras, afunilando-se mais os tipos de famílias que nelas residem.

0 questionário era composto por sete seções distintas, oscilando entre sete e 10 perguntas em cada uma, que, no seu conjunto, perfaziam um total de 60 questões. Da abrangência da informação recolhida, selecionamos as seções referentes à matéria tratada neste artigo. ${ }^{6}$ Desse modo, a análise dos resultados divide-se em dois blocos principais: um no qual se avaliam os impactos da crise, entre 2008 e 2014, no emprego e na contração do acesso a fontes de rendimentos; e outro, direcionado para observar o aprofundamento das condições de exclusão associadas à vulnerabilidade no acesso a bens de consumo essenciais (alimentação, vestuário e calçado e eletricidade e gás).

\section{Vulnerabilidades das famílias no acesso a rendimentos e aumento do desemprego}

Agrupando as famílias por escalões de rendimento (Figura 1), a situação do sistema urbano reproduz uma distribuição dentro da seguinte ordem de grandeza: $17,3 \%$ das famílias vivem com menos de 500 euros $(\mathrm{R} \$ 1.692,00)^{7}$ por mês; $37,2 \%$ conflui para o escalão dos 500 a 1.000 euros (de $R \$ 1.692,00$ a $R \$ 3.385,00$ ) por mês; $32,8 \%$ possui rendimentos entre os 1.000 e os 2.500 euros (de $R \$ 3.385,00$ a $R \$ 8.462$ ) e $11,4 \%$ usufrui de rendimentos mensais superiores a 2.500 euros $(\mathrm{R} \$ 8.462,00)$.

Figura 1 - Desagregação dos agregados familiares do Sistema Urbano do Oeste e dos 4 centros urbanos por escalões de rendimento mensal

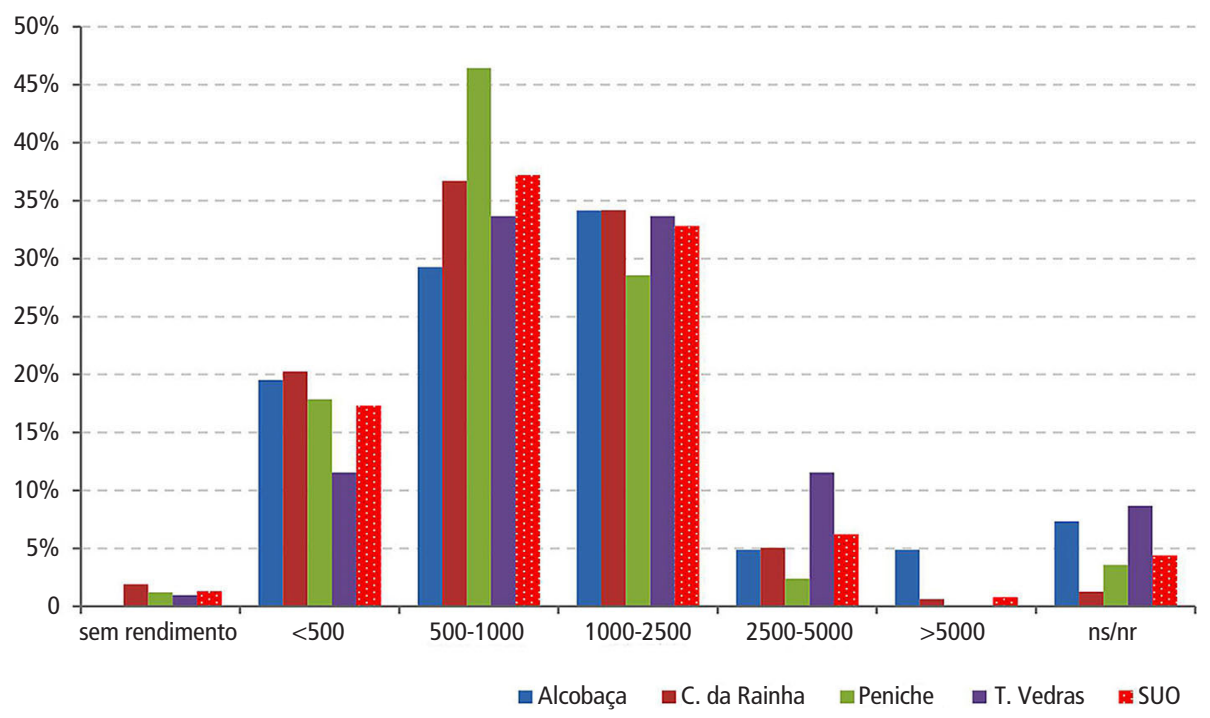

Fonte: questionários, 2014, elaboração do autor. 
Juntando as três classes mais baixas, por um lado, e as três mais elevadas, por outro, obtemos uma primeira camada de análise que criva, de modo mais fácil, as quatro cidades em estudo. No conjunto do sistema urbano do Oeste (SUO), no qual se integram as quatro cidades, para cada família cujo rendimento é superior a 1.000 euros existe 1,4 famílias cujo rendimento se posiciona abaixo desse limiar. Nas diferentes cidades, essa relação assume os valores de 2,1 em Peniche; 1,5 nas Caldas da Rainha; 1,1 em Alcobaça; e 1,0 em Torres Vedras. Esse indicador diferencia, de modo mais evidente, os centros urbanos de Peniche, com maior desequilíbrio, e Torres Vedras, onde ambos os estratos se sobrepõem.

Apesar de se reconhecer a utilidade dessa primeira camada da avaliação, ao não discriminar a dimensão do agregado familiar, essa medida não reproduz a ponderação desses rendimentos pelos indivíduos que integram as respetivas famílias, o que debilita a sua aderência à realidade que cada uma enfrenta. Para suprir essa lacuna, foi determinado o ponto central da classe de rendimentos indicados pelos entrevistados, e esse valor foi distribuído pelo número de indivíduos que compõem o agregado familiar. Desse modo, obteve-se uma medida que se aproxima do que se pode denominar "rendimento familiar mensal per capita".

Partindo os valores resultantes em três "fatias", na primeira foram concentradas as famílias cujo rendimento mensal per capita se posiciona até os 437,5 euros/mês ${ }^{8}$ (1.481 reais/ mês); na segunda, as famílias que possuem rendimento domiciliar mensal per capita entre 499 euros (1.689 reais) e 750 euros (2.538 reais) a cada um. Na terceira linha, denominada "total parcial", apresentam-se as famílias que podem atribuir mais de 875 euros (2.962 reais) por mês a cada um dos indivíduos.

Com essa matriz de referência (Tabela 1), constata-se que, no sistema urbano do Oeste, $54,3 \%$ das famílias não conseguem atribuir, por mês, mais de 438 euros a cada um dos seus elementos (31\% das famílias obtêm rendimentos que não proporcionam mais de 250 euros/ mês per capita). Diga-se que a população em risco de pobreza definido para o ano de 2012 posicionava-se nos 18,7\% (Rede Europeia Anti-pobreza, 2014).

A cidade de Peniche demonstra uma situação mais frágil, uma vez que quase $68 \%$ das famílias se posicionam no primeiro patamar (menos de 437,5 euros mensais per capita), e $37 \%$ não atinge o limiar dos 250 euros mensais per capita). Segue-se Caldas da Rainha, onde $56,3 \%$ das famílias não atingem os patamares considerados (33,5\% não atingem o limiar dos 250 euros mensais per capita). Alcobaça e Torres Vedras, ainda assim, ocupam posições menos desfavoráveis, $51,2 \%$ e $42,3 \%$, respectivamente $(27 \%$ e $22 \%$ se forem considerados como teto 250 euros mensais per capita).

Em suma, na maioria dos casos (os referentes ao primeiro patamar), os elementos que integram os núcleos familiares dessas cidades vivem com cerca de 8 euros/dia (14,59\% tendo em conta a fasquia dos 437,5 euros mensais per capita). Note-se que é desse rendimento que se subtraem as parcelas correspondentes a todas as rubricas de custos que as famílias suportam. Contrapondo o número de famílias que dispõem de menos de 437,5 euros mensais per capita pelas que possuem mais de 499 euro mensais, resulta a seguinte distribuição: 1,2 em Alcobaça; 1,4 em Caldas da Rainha; 2,3 em Peniche; e 0,9 em Torres Vedras. 
Tabela 1 - Rendimento familiar mensal disponível para cada indivíduo do agregado

\begin{tabular}{|c|c|c|c|c|c|}
\hline Euro/per capita & $\begin{array}{c}\text { Alcobaça } \\
-\%\end{array}$ & $\begin{array}{l}\text { Caldas da } \\
\text { Rainha - \% }\end{array}$ & $\begin{array}{c}\text { Peniche } \\
-\%\end{array}$ & $\begin{array}{c}\text { Torres Vedras } \\
-\%\end{array}$ & $\begin{array}{c}\text { Sistema Urbano } \\
\text { do Oeste - \% }\end{array}$ \\
\hline 99,8 & 0,0 & 0,6 & 0,0 & 0,0 & 0,3 \\
\hline 124,8 & 7,3 & 0,0 & 2,4 & 0,0 & 1,3 \\
\hline 125,0 & 0,0 & 0,6 & 0,0 & 0,0 & 0,3 \\
\hline 150,0 & 2,4 & 1,3 & 1,2 & 1,0 & 1,3 \\
\hline 166,3 & 2,4 & 3,8 & 1,2 & 0,0 & 2,1 \\
\hline 187,5 & 4,9 & 5,7 & 8,3 & 2,9 & 5,4 \\
\hline 249,5 & 2,4 & 8,9 & 11,9 & 5,8 & 8,0 \\
\hline 250,0 & 7,3 & 12,7 & 11,9 & 12,5 & 11,9 \\
\hline 291,7 & 0,0 & 0,6 & 0,0 & 1,0 & 0,5 \\
\hline 350,0 & 2,4 & 3,2 & 1,2 & 1,0 & 2,1 \\
\hline 375,0 & 12,2 & 11,4 & 19,0 & 12,5 & 13,4 \\
\hline 437,5 & 9,8 & 7,6 & 9,5 & 5,8 & 7,8 \\
\hline total parcial & 51,2 & 56,3 & 66,7 & 42,3 & 54,3 \\
\hline 499,0 & 7,3 & 7,0 & 2,4 & 5,8 & 5,7 \\
\hline 583,3 & 9,8 & 12,0 & 9,5 & 9,6 & 10,6 \\
\hline 625,0 & 0,0 & 0,0 & 0,0 & 1,0 & 0,3 \\
\hline 750,0 & 2,4 & 5,7 & 6,0 & 4,8 & 5,2 \\
\hline total parcial & 19,5 & 24,7 & 17,9 & 21,2 & 21,7 \\
\hline 875,0 & 12,2 & 8,9 & 6,0 & 14,4 & 10,1 \\
\hline 937,5 & 0,0 & 1,9 & 1,2 & 2,9 & 1,8 \\
\hline 1000,0 & 2,4 & 0,0 & 0,0 & 0,0 & 0,3 \\
\hline 1250,0 & 0,0 & 0,0 & 1,2 & 5,8 & 1,8 \\
\hline 1750,0 & 0,0 & 1,9 & 2,4 & 1,9 & 1,8 \\
\hline 1875,0 & 4,9 & 2,5 & 0,0 & 1,9 & 2,1 \\
\hline 2500,0 & 2,4 & 0,6 & 0,0 & 0,0 & 0,5 \\
\hline total parcial & 22,0 & 15,8 & 10,7 & 26,9 & 18,3 \\
\hline Não sabe ou não responde (ns/nr) & 7,3 & 3,2 & 4,8 & 9,6 & 5,7 \\
\hline Total geral & 100 & 100 & 100 & 100 & 100 \\
\hline
\end{tabular}

Fonte: questionários, 2014, elaboração do autor.

Cabe notar que as tipologias de famílias que vivem essa situação de maior vulnerabilidade são casais sem filhos (24\%), casais com um filho (24\%), monoparentais com um filho
(18\%) e casais com dois filhos (10,5\%). Isto é, boa parte das famílias que se encontram nestas situações de grande vulnerabilidade tem crianças a cargo. 


\section{Crise pós-2008 e contração das fontes de rendimentos}

Com as duas linhas de análise seguintes, pretendemos apurar o impacto da crise nos rendimentos das famílias e a sua percepção quanto à estabilidade desses mesmos rendimentos. Para tal, perguntava-se se, nos 6 anos em cau$\mathrm{sa}$, os rendimentos da família mantiveram-se, aumentaram ou diminuíram. Quando as respostas apontavam para uma das duas últimas hipóteses, pedia-se que indicassem se aumentaram/diminuíram até $1 / 4$, entre $1 / 4$ e metade ou mais/menos do que a metade (Figura 2).

Apesar de em menor número, foi possível identificar famílias que aumentaram os seus rendimentos no decurso do período da crise estudado ( $8 \%$ dos casos); dentro dessa situação, o mais comum $(6,7 \%)$ é que a ordem de grandeza desse aumento seja de $1 / 4$. Percebe-se, ainda, que um pouco mais de uma família em cada quatro $(26,1 \%)$ responde que o montante do seu rendimento não sofreu oscilações.

Considerando os casos restantes, conclui-se que, na maioria das vezes, as famílias vivenciaram reduções de rendimentos no período em causa $(65,4 \%)$. Essa redução corresponde maioritariamente a cerca de $1 / 4$ do que dispunham no início do período de crise (em $38,5 \%$ dos casos). Contudo, é significativo 0 fato de quase uma em cada cinco famílias terem reportado reduções no seu rendimento entre $1 / 4$ e $1 / 2$ do que dispunham e quase

Figura 2 - Impacto da crise pós-2008 nos rendimentos familiares

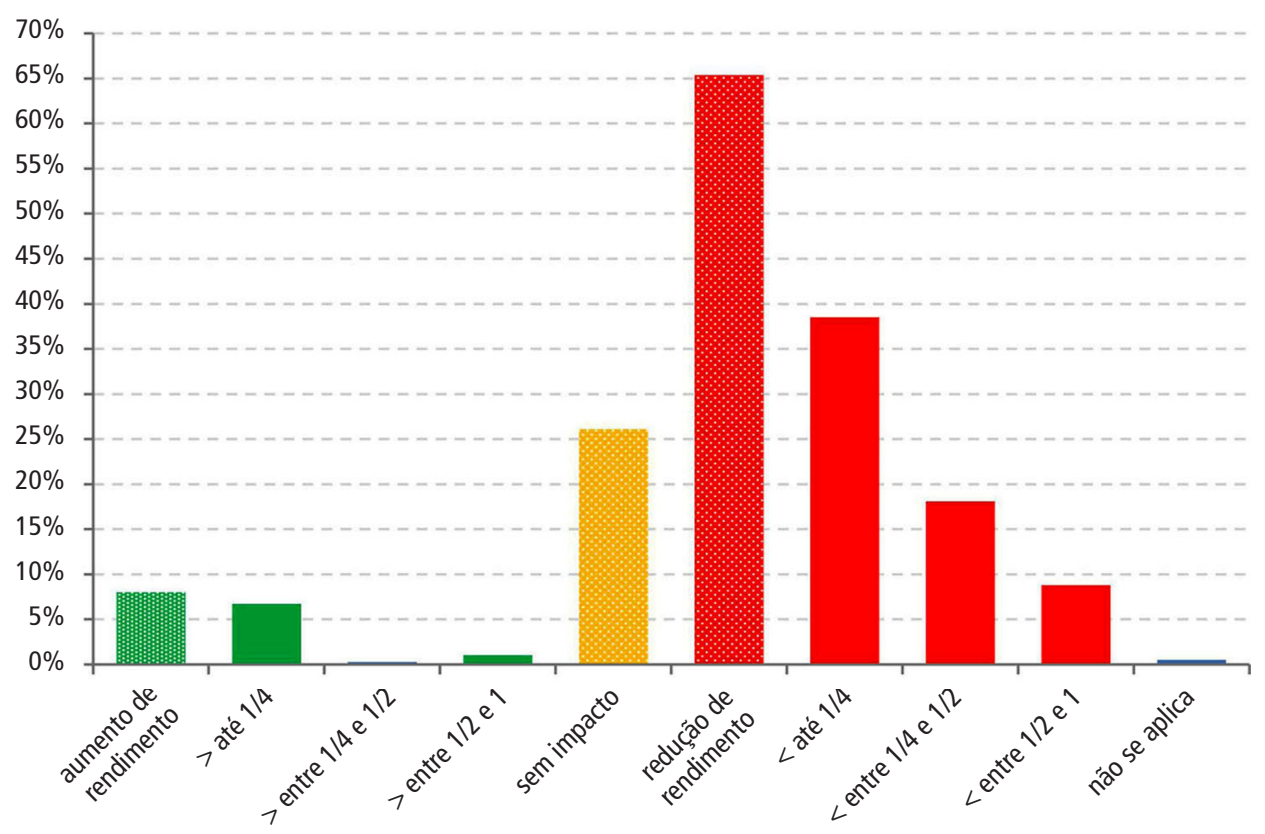


9\% experienciem cortes de mais de $1 / 2$ do orçamento mensal (Figura 2). Nessa situação, estão famílias de funcionários púbicos, mas também de comerciantes, bancários e de empregados de balcão.

Tem relevância ainda o fato de $61 \%$ dos reformados e pensionistas terem declarado que viram os seus rendimentos diminuírem no decurso desses seis anos. Se a estes se juntarem os que mantiveram o rendimento, o valor percentual sobe para $97 \%$. É o mesmo que dizer que apenas $3 \%$ das famílias aumentaram os rendimentos nessa fase da crise.

Para cada família que manteve o seu rendimento ou que teve seu rendimento aumentado, existem quase duas que viram as suas fontes de rendimento diminuir de modo muito significativo. Executando o exercício de divisão do número de famílias que tiveram seu rendimento reduzido, pelas famílias tiveram seu rendimento ampliado, obtêm-se estes resultados: 14 famílias em regressão para cada uma em expansão em Alcobaça; 5,6 em Caldas da Rainha; 14 em Peniche; e 9,9 em Torres Vedras. Nesse indicador, está refletido o impacto que a crise provocou nas famílias que vivem nesses centros urbanos. Essa situação decorre das alterações (de várias ordens), introduzidas no mercado de trabalho.

Remata-se esse ponto dizendo que, mais de metade dos respondentes considera que 0 rendimento familiar é instável $(57,1 \%)$, contra os $37,7 \%$ que percepcionam estabilidade no rendimento da sua família (Figura 3).

Figura 3 - Perceção sobre a estabilidade/instabilidade dos rendimentos

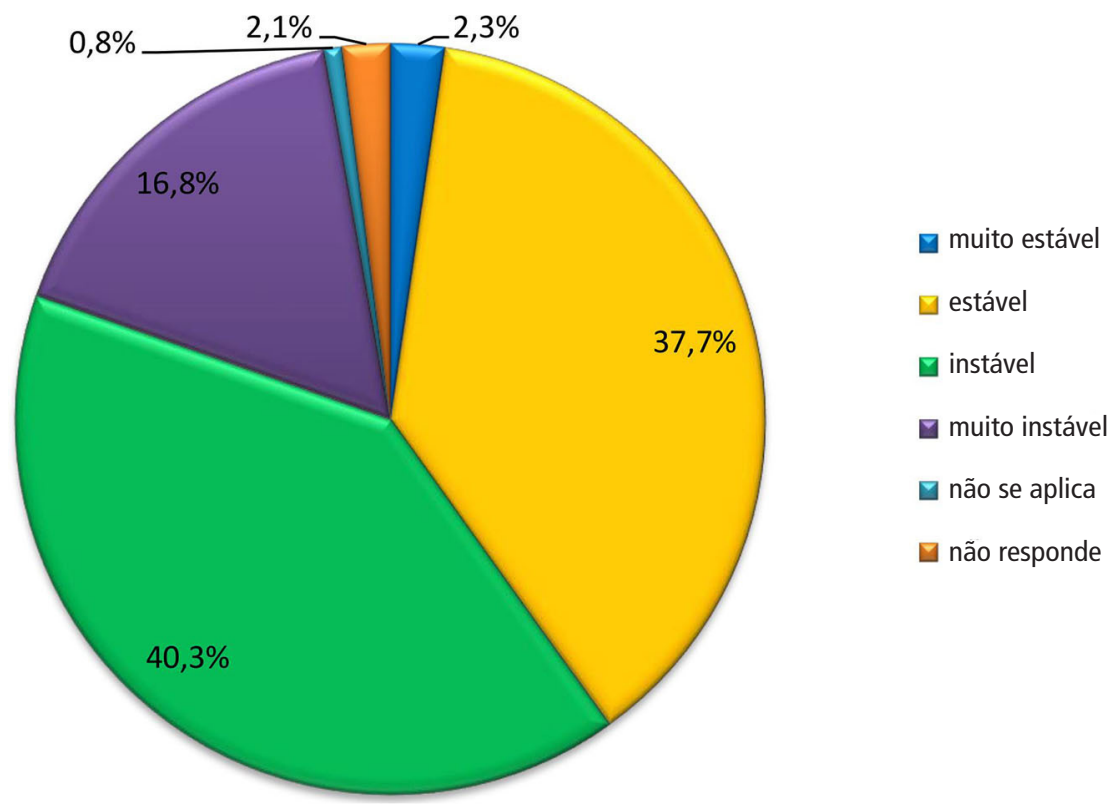

Fonte: questionários, 2014, elaboração do autor. 
Em Peniche, para cada família que antevê estabilidade nos rendimentos, existe 1,7 que vislumbra instabilidade, o valor correspondente é: em Torres Vedras 1,5; e em Alcobaça e Caldas da Rainha 1,3. Essa instabilidade está associada à indefinição política que confere consistência à possibilidade de poderem perder rendimentos ou porque as situações de desemprego não estão afastadas do horizonte de possibilidades com que as famílias se deparam no futuro próximo. Vejamos de seguida a expressão que essas situações fazem no conjunto das famílias para as quais obtivemos informação.

\section{Crise pós-2008 e aumento do desemprego}

Para se estabelecer a base de ponderação das situações de desemprego, deve-se considerar o resultado da subtração aos ativos (empregados e desempregados), as parcelas correspondentes aos reformados e pensionistas. Daqui resulta uma taxa de desemprego superior a $23 \%$, no cômputo do sistema urbano do Oeste. 0 mesmo será dizer que, a cada quatro ativos, quase um está em situação de desemprego.

Dentro do grupo dos que estavam desempregados, 37,7\% estavam nessa situação há menos de um ano; e 25,4\% entre um ano e dois. Mais notório é o fato de $37 \%$ dos casos corresponderem a situações de desemprego cujo tempo de duração supera os dois anos. Dos que estavam desempregados há menos de um ano, 44,2\% não transpuseram o $9^{\circ}$ ano de escolaridade no seu percurso escolar, 55,8\% completaram o ensino secundário ou o superior. No grupo dos desempregados entre um e dois anos, a situação inverte-se na proporção de $63 \%$ para $37 \%$, mantendo a partição utilizada anteriormente. Relativamente aos desempregados há mais de dois anos, a situação é semelhante (Figura 4).

Figura 4 - Ponderação (\%) dos desempregados por nível de instrução e tempo de permanência

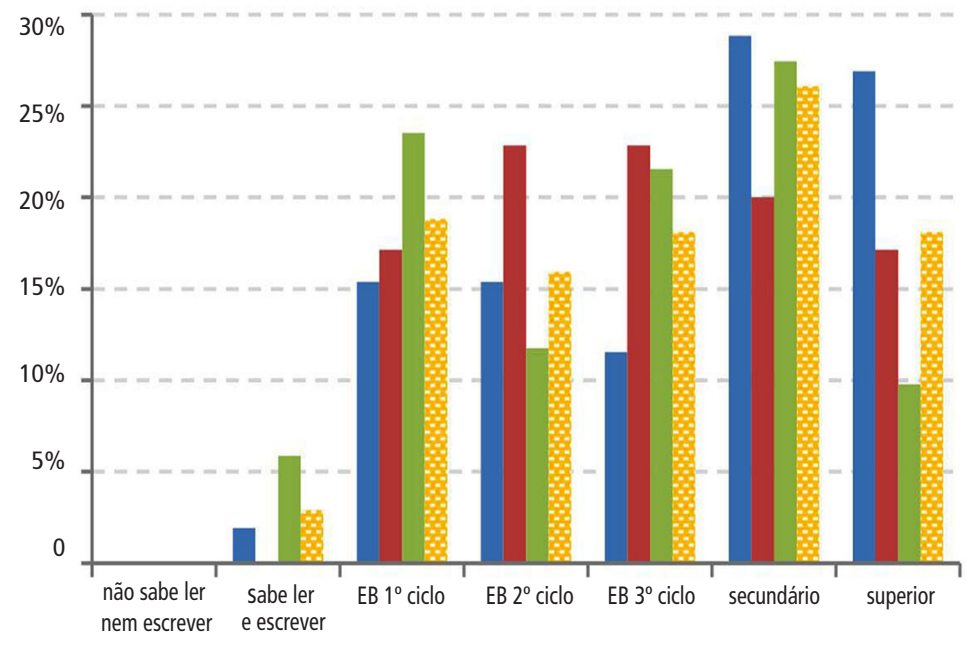

desempregado há menos de 1 ano

desempregado entre 1 e 2 anos desempregado há mais de 2 anos

total agregado

Fonte: questionários, 2014, elaboração do autor. 
Decorre daqui a conclusão de que, no sistema urbano em estudo, as situações de desemprego com menos duração são mais usuais quando as pessoas têm mais formação, invertendo-se quando se têm em conta as situações em que o tempo de permanência, em situação de desemprego, é maior (Figura 4). 0 mesmo é dizer que a estrutura econômica absorve melhor os ativos menos preparados, embora o fato de em especial os licenciados com mais de dois anos de desemprego assumirem menor representatividade possa indiciar maior rotatividade entre situações de atividade/inatividade ou maior propensão para a emigração.

Quais as classes profissionais mais afetadas pelo desemprego? Pelo que se apurou (Tabela 2), arrumando os casos registados pelos grandes grupos de profissões (Classificação Nacional de Profissões - CNP), tendo em conta a última profissão desempenhada, é notório que são os empregados dos setores de serviços e vendedores aqueles mais atingidos (26\%); os operários, os especialistas das profissões intelectuais e científicas são a segunda categoria mais afetada (18\%); e os artesãos e profissões similares são a terceira categoria (17\%) visada (Tabela 2).

Os setores dos serviços, comércio (por exemplo, vendedores e empregados de balcão) e indústria (operários fabris) são os mais afetados pelo desemprego. Agregando as três classes em que é suposta uma qualificação maior, obtemos um peso relativo de $22,6 \%$ no número de desempregados. Digamos que as profissões menos qualificadas (categorias de 4 a 9, da CNP) concentram 3,6 vezes mais desempregados do que as mais qualificadas. Uma nota para os $10 \%$ de casos que correspondem a situações de procura do primeiro emprego ou ainda de outros em que as atividades anteriores, pelo caráter de desqualificação e de ocasionalidade não permitiram definir uma profissão.

Essa fragilidade é ainda mais expressiva se tomarmos em conta que a maior parte das situações de desemprego sinalizadas (71\%) não recebe subsídio de desemprego. ${ }^{9}$ Mesmo atendendo ao fato de, em alguns desses casos, essa ausência de salário ao fim do mês ser compensada pelo rendimento social de inserção, ${ }^{10}$ o peso dos que não acedem a qualquer tipo de ganho, por via da incapacidade de aceder a emprego, mesmo caindo para os $67 \%$, mantém uma preponderância inequívoca (Tabela 3).

Quando questionados sobre as probabilidades que tinham de poder vir a conseguir um novo emprego, mantendo o rendimento que tinham no precedente (Figura 5), os entrevistados revelaram-se bastante céticos, porquanto, de modo geral, a resposta revela que ambas as possibilidades (aceder a um novo emprego mantendo o rendimento anterior ou conseguir esse novo emprego na cidade de residência) são encaradas como "muito baixas" (53\% e $58 \%$ respetivamente).

Para inventariar as vivências de situações de desemprego pós-2008, perguntou-se se, nesse período, alguém da família passou por situações de desemprego. Apurou-se que tal evento tocou à porta de algum (ou de alguns) dos seus membros em $36 \%$ das famílias. No cômputo da amostra ampliada, tomando em conta o somatório dos indivíduos em idade ativa, percebe-se que, ao quantitativo de desempregados encontrado no momento da entrevista, acresce-se o fato de cerca de 19\% dos ativos terem passado por situações de desemprego nos seis anos estudados. 


\section{Tabela 2 - Distribuição dos desempregados (\%) por grandes grupos de profissões tendo em conta a última profissão desempenhada}

\begin{tabular}{|c|c|c|c|c|c|c|c|c|c|c|}
\hline \multirow{2}{*}{$\begin{array}{c}\text { Classificação nacional } \\
\text { de profissões } \\
\text { (Grandes Grupos) }\end{array}$} & \multicolumn{2}{|c|}{ Alcobaça } & \multicolumn{2}{|c|}{$\begin{array}{l}\text { Caldas da } \\
\text { Rainha }\end{array}$} & \multicolumn{2}{|c|}{ Peniche } & \multicolumn{2}{|c|}{ Torres Vedras } & \multicolumn{2}{|c|}{$\begin{array}{c}\text { Total no } \\
\text { sistema urbano } \\
\text { do Oeste }\end{array}$} \\
\hline & $n^{\circ}$ & $\%$ & $n^{0}$ & $\%$ & $n^{\circ}$ & $\%$ & $n^{\circ}$ & $\%$ & $n^{\circ}$ & $\%$ \\
\hline $\begin{array}{l}\text { Quadros superiores da } \\
\text { administração pública, } \\
\text { dirigentes e quadros } \\
\text { superiores de empresa }\end{array}$ & 1 & 1,1 & 15 & 5,3 & 4 & 2,5 & 13 & 6,7 & 33 & 4,6 \\
\hline $\begin{array}{l}\text { Especialistas das profissões } \\
\text { intelectuais e científicas }\end{array}$ & 17 & 19,3 & 49 & 17,4 & 15 & 9,5 & 49 & 25,4 & 130 & 18,0 \\
\hline $\begin{array}{l}\text { Técnicos e profissionais de } \\
\text { nível intermédio }\end{array}$ & 5 & 5,7 & 19 & 6,8 & 7 & 4,4 & 15 & 7,8 & 46 & 6,4 \\
\hline $\begin{array}{l}\text { Pessoal administrativo e } \\
\text { similares }\end{array}$ & 10 & 11,4 & 30 & 10,7 & 18 & 11,4 & 21 & 10,9 & 79 & 11,0 \\
\hline $\begin{array}{l}\text { Pessoal dos serviços e } \\
\text { vendedores }\end{array}$ & 21 & 23,9 & 80 & 28,5 & 48 & 30,4 & 37 & 19,2 & 187 & 25,9 \\
\hline $\begin{array}{l}\text { Agricultores e trabalhadores } \\
\text { qualificados da agricultura } \\
\text { e pescas }\end{array}$ & 2 & 2,3 & 6 & 2,1 & 12 & 7,6 & 1 & 0,5 & 21 & 2,9 \\
\hline $\begin{array}{l}\text { Operários, artífices e } \\
\text { trabalhadores similares }\end{array}$ & 17 & 19,3 & 45 & 16,0 & 33 & 20,9 & 27 & 14,0 & 122 & 16,9 \\
\hline $\begin{array}{l}\text { Operadores de instalações e } \\
\text { máquinas e trabalhadores da } \\
\text { montagem }\end{array}$ & 3 & 3,4 & 6 & 2,1 & 5 & 3,2 & 6 & 3,1 & 20 & 2,8 \\
\hline $\begin{array}{l}\text { Trabalhadores não } \\
\text { qualificados }\end{array}$ & 12 & 13,6 & 31 & 11,0 & 16 & 10,1 & 24 & 12,4 & 83 & 11,5 \\
\hline Total parcial & 88 & 100,0 & 281 & 100,0 & 158 & 100,0 & 193 & 100,0 & 721 & 100,0 \\
\hline Não se aplica & 22 & & 75 & & 31 & & 55 & & 183 & \\
\hline Não sabe ou não responde & & & 20 & & 9 & & 1 & & 30 & \\
\hline Sem profissão definida & 3 & & 46 & & 26 & & 19 & & 94 & \\
\hline Total geral & 113 & & 422 & & 224 & & 268 & & 1.028 & \\
\hline
\end{tabular}

Fonte: questionários, 2014, elaboração do autor. 
Tabela 3 - Desempregados benificiários e não benificiários de desemprego subsidiado

\begin{tabular}{|c|c|c|c|c|c|}
\hline \multirow{3}{*}{ Grupos etários } & \multicolumn{5}{|c|}{ Recebe subsídio de desemprego } \\
\hline & \multicolumn{2}{|c|}{ Sim } & \multicolumn{2}{|c|}{ Não } & \multirow{2}{*}{$\frac{\mathrm{RS}}{\%}$} \\
\hline & $\mathrm{N}^{\circ}$ & $\%$ & $\mathrm{~N}^{\circ}$ & $\%$ & \\
\hline $15-19$ & 1 & 2,6 & 5 & 5,4 & - \\
\hline $20-24$ & 2 & 5,3 & 10 & 10,8 & 1 \\
\hline $25-29$ & 1 & 2,6 & 19 & 20,4 & - \\
\hline $30-34$ & 6 & 15,8 & 7 & 7,5 & 1 \\
\hline $35-39$ & 5 & 13,2 & 8 & 8,6 & 1 \\
\hline $40-44$ & 2 & 5,3 & 4 & 4,3 & 2 \\
\hline $45-49$ & 9 & 23,7 & 8 & 8,6 & - \\
\hline $50-54$ & 5 & 13,2 & 11 & 11,8 & - \\
\hline $55-59$ & 6 & 15,8 & 11 & 11,8 & - \\
\hline $60-64$ & 1 & 2,6 & 6 & 6,5 & - \\
\hline $65-69$ & - & 0,0 & 3 & 3,2 & - \\
\hline $70-74$ & - & 0,0 & 1 & 1,1 & - \\
\hline Total geral & 38 & 100,0 & 93 & 100,0 & 5 \\
\hline
\end{tabular}

Fonte: questionários, 2014, elaboração do autor.

Figura 5 - Probabilidade de aceder a emprego na cidade de residência

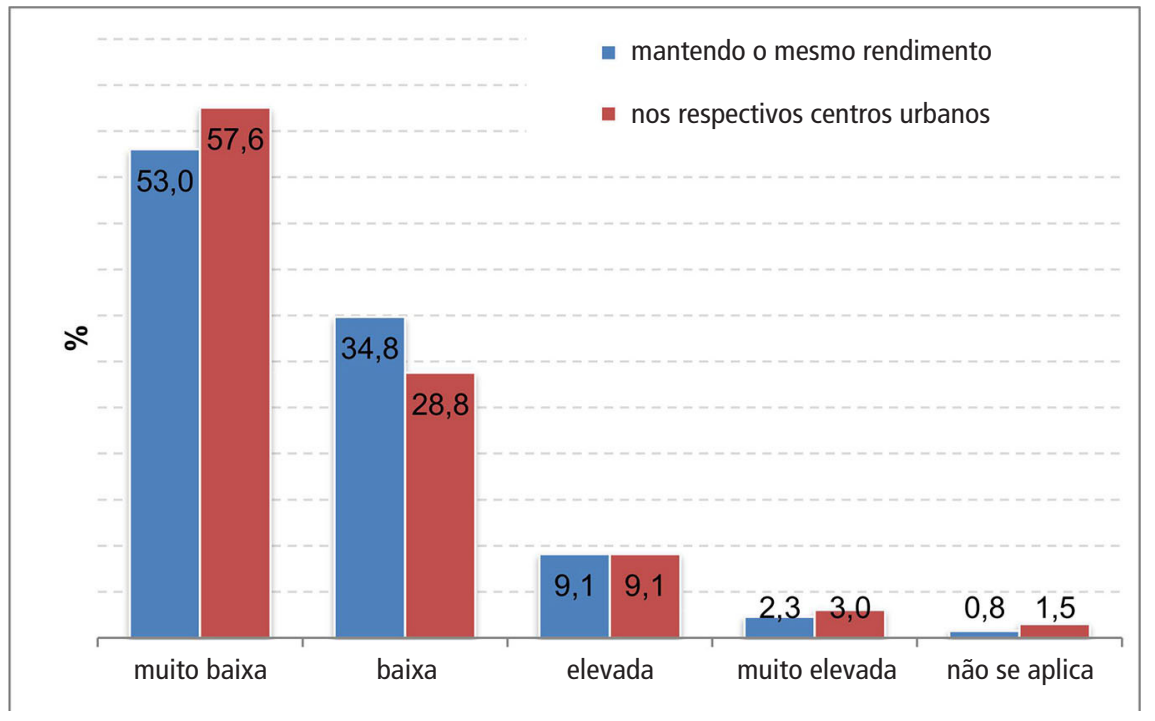

Fonte: questionários, 2014, elaboração do autor. 
A situação de vulnerabilidade decorrente das alterações nas fontes de rendimento, materializa-se na constatação de que apenas em $15 \%$ dos casos, quando esses membros do agregado familiar voltaram ao mercado de trabalho, o salário aumentou. No verso dessa situação, em $32 \%$ das vezes, o salário diminuiu e, em $16 \%$ das situações, as pessoas não voltaram ao mercado de trabalho (uns esperaram alguns anos e reformaram-se, e outros desistiram de procurar emprego no País e emigraram).

Vejamos, em seguida, o que se apurou para os diferentes centros urbanos. Importa reter que a taxa de desemprego perspectivada, segundo os critérios estabelecidos no final de 2014, assumia, no contexto do País, a marca dos $18,5 \%$. São mais expressivas as taxas de desemprego calculadas a partir dos dados recolhidos nas entrevistas, pois não se atêm ao número de inscritos nos Centros de Emprego, ${ }^{11}$ manifestando-se, dessa maneira, disponíveis para trabalhar (como se viu, uma parte significativa não recebe subsídio de emprego, sobretudo os de longa duração, o que leva a crer que não estão inscritos no Centro de Emprego, saindo, assim, do âmbito estatístico).

A taxa mais elevada de desemprego foi detectada na cidade das Caldas da Rainha, onde o peso dos desempregados atinge os $28,3 \%$ dos ativos que compõem a amostra ampliada. Alcobaça e Peniche apresentam taxas entre os $21 \%$ e os $22 \%$. A cidade de Torres Vedras apresenta-se com situação mais favorável, apontando para valores na ordem dos $17 \%$. Tal situação não pode ser apartada da maior extensão da bacia de emprego e da, também maior, robustez da estrutura de habilitações dos ativos (Tabela 4).
Uma parte destas situações de desemprego dá azo a fluxos de emigração. Os dados recolhidos demonstram que $29,2 \%$ das famílias que residem nesses centros urbanos viram familiares (em $71 \%$ dos casos, a relação de parentesco é direta: filho/a, pai/ mãe, irmão/irmã) emigrar no decurso dos seis anos analisados.

\section{Vulnerabilidades das famílias no acesso a bens essenciais e exclusão social}

\section{Crise pós-2008 e contração do consumo de bens essenciais}

A contração e/ou alteração dos hábitos de consumo provocados pela crise conduz-nos a um nível mais ramificado de mudanças, expondo os constrangimentos que as famílias sentem para a obtenção de bens (alimentação, vestuário, eletricidade e gás).

A questão colocada foi: desde que estamos em crise, a sua família teve de reduzir despesas? Feita a questão, de âmbito totalmente aberto, o mais comum foi a recolha de respostas afirmativas ( $85 \%$ no conjunto das 4 cidades: $86 \%$ em Caldas da Rainha e Peniche; $85 \%$ em Torres Vedras; e 78\% em Alcobaça). Certo é que a latitude da questão não se presta a outra conclusão que não seja: estamos em presença de um movimento geral de contração do consumo (Tabela 5).

Desagregando essa primeira questão em diferentes rubricas, confrontamos os entrevistados com seis itens (na sequência apresentada). 
Tabela 4 - Taxa de desemprego (nos centros urbanos e no Sistema Urbano do Oeste-SUO)

\begin{tabular}{|c|c|c|c|c|c|c|c|c|c|}
\hline & & $\begin{array}{l}\text { Não sabe } \\
\text { ler nem } \\
\text { escrever }\end{array}$ & $\begin{array}{c}\text { Sabe ler } \\
\text { e } \\
\text { escrever }\end{array}$ & $\begin{array}{c}\text { EB } \\
1^{\circ} \text { ciclo }\end{array}$ & $\begin{array}{c}\text { EB } \\
2^{\circ} \text { ciclo }\end{array}$ & $\begin{array}{c}\text { EB } \\
3^{\circ} \text { ciclo }\end{array}$ & Secundário & Superior & $\begin{array}{l}\text { Total } \\
\text { geral }\end{array}$ \\
\hline $\begin{array}{l}\text { ত্তু } \\
\frac{0}{0} \\
\frac{0}{0} \\
\frac{U}{4}\end{array}$ & $\begin{array}{l}\text { ativos } \\
\text { desempregados } \\
\text { taxa de desemprego }\end{array}$ & $\begin{array}{l}0 \\
0 \\
0\end{array}$ & $\begin{array}{c}1 \\
1 \\
100,0\end{array}$ & $\begin{array}{r}9 \\
1 \\
11,1\end{array}$ & $\begin{array}{c}8 \\
3 \\
37,5\end{array}$ & $\begin{array}{c}14 \\
3 \\
21,4\end{array}$ & $\begin{array}{c}18 \\
2 \\
11,1\end{array}$ & $\begin{array}{c}16 \\
4 \\
25,0\end{array}$ & $\begin{array}{r}66 \\
14 \\
21,2\end{array}$ \\
\hline$\frac{\pi}{\frac{\pi}{0}} \frac{\stackrel{0}{\frac{\pi}{n}}}{\frac{\pi}{\pi}}$ & $\begin{array}{l}\text { ativos } \\
\text { desempregados } \\
\text { taxa de desemprego }\end{array}$ & $\begin{array}{l}1 \\
0 \\
0\end{array}$ & $\begin{array}{c}2 \\
2 \\
100,0\end{array}$ & $\begin{array}{c}28 \\
15 \\
53,6\end{array}$ & $\begin{array}{c}30 \\
13 \\
43,3\end{array}$ & $\begin{array}{r}46 \\
12 \\
26,1\end{array}$ & $\begin{array}{c}89 \\
19 \\
21,3\end{array}$ & $\begin{array}{r}58 \\
11 \\
19,0\end{array}$ & $\begin{array}{r}254 \\
72 \\
28,3\end{array}$ \\
\hline 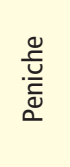 & $\begin{array}{l}\text { ativos } \\
\text { desempregados } \\
\text { taxa de desemprego }\end{array}$ & $\begin{array}{l}0 \\
0\end{array}$ & $\begin{array}{l}4 \\
1\end{array}$ & $\begin{array}{c}19 \\
8 \\
42,1\end{array}$ & $\begin{array}{c}22 \\
2 \\
9,1\end{array}$ & $\begin{array}{r}33 \\
4 \\
12,1\end{array}$ & $\begin{array}{c}28 \\
9 \\
32,1\end{array}$ & $\begin{array}{c}24 \\
4 \\
16,7\end{array}$ & $\begin{array}{r}130 \\
28 \\
21,5\end{array}$ \\
\hline 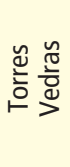 & $\begin{array}{l}\text { ativos } \\
\text { desempregados } \\
\text { taxa de desemprego }\end{array}$ & $\begin{array}{l}0 \\
0 \\
0\end{array}$ & $\begin{array}{l}0 \\
0 \\
0\end{array}$ & $\begin{array}{c}19 \\
2 \\
10,5\end{array}$ & $\begin{array}{c}15 \\
4 \\
26,7\end{array}$ & $\begin{array}{c}23 \\
6 \\
26,1\end{array}$ & $\begin{array}{c}32 \\
6 \\
18,8\end{array}$ & $\begin{array}{c}56 \\
6 \\
10,7\end{array}$ & $\begin{array}{r}145 \\
24 \\
16,6\end{array}$ \\
\hline$\stackrel{\circ}{\curvearrowright}$ & $\begin{array}{l}\text { ativos } \\
\text { desempregados } \\
\text { taxa de desemprego }\end{array}$ & 0,0 & 57,1 & $\begin{array}{c}75 \\
26 \\
34,7\end{array}$ & $\begin{array}{r}75 \\
22 \\
29,3\end{array}$ & $\begin{array}{c}116 \\
25 \\
21,6\end{array}$ & $\begin{array}{r}167 \\
36 \\
21,6\end{array}$ & $\begin{array}{c}154 \\
25 \\
16,2\end{array}$ & $\begin{array}{r}595 \\
138 \\
23,2\end{array}$ \\
\hline
\end{tabular}

Fonte: questionários, 2014, elaboração do autor .

Registrando, sucessivamente, o sentido das respostas apresentadas para cada uma delas, será possível avançar um pouco mais.

Observando a tríade de bens essenciais (Figura 6), a cada quatro famílias entrevistadas, apenas uma afirma que não reduziu o consumo em nenhuma das rubricas apontadas. Os valores calculados para os centros urbanos são muito próximos dessa fasquia. Destaque para o caso das Caldas da Rainha onde há menos famílias que não reduziram o nível de consumo. No avesso dessa realidade, encontramos, com uma proporção semelhante (24\%), as famílias que reduziram o consumo nos três itens, denunciando situações de maior exposição aos efeitos da crise. 
Tabela 5 -- Matriz de contração do consumo de bens essenciais

\begin{tabular}{|c|c|c|c|c|c|c|c|c|c|c|c|c|}
\hline \multicolumn{3}{|c|}{ Reduziu custos com: } & \multicolumn{2}{|c|}{ Alcobaça } & \multicolumn{2}{|c|}{$\begin{array}{c}\text { Caldas } \\
\text { da Rainha }\end{array}$} & \multicolumn{2}{|c|}{ Peniche } & \multicolumn{2}{|c|}{$\begin{array}{l}\text { Torres } \\
\text { Vedras }\end{array}$} & \multicolumn{2}{|c|}{$\begin{array}{c}\text { Sistema Urbano } \\
\text { do Oeste }\end{array}$} \\
\hline Alimentação & $\begin{array}{c}\text { Vestuário/ } \\
\text { calçado }\end{array}$ & $\begin{array}{c}\text { Eletricidade/ } \\
\text { gás }\end{array}$ & $\mathrm{N}^{\circ}$ & $\%$ & $\mathrm{~N}^{\circ}$ & $\%$ & $\mathbf{N}^{\circ}$ & $\%$ & $\mathrm{~N}^{\circ}$ & $\%$ & $\mathbf{N}^{\circ}$ & $\%$ \\
\hline não reduziu & não reduziu & não reduziu & 11 & 26,8 & 37 & 23,4 & 22 & 26,2 & 27 & 26,0 & 97 & 25,1 \\
\hline não reduziu & não reduziu & não reduziu & 14 & 34,1 & 32 & 20,3 & 18 & 21,4 & 28 & 26,9 & 92 & 23,8 \\
\hline não reduziu & reduziu & reduziu & 1 & 2,4 & 21 & 13,3 & 10 & 11,9 & 14 & 13,5 & 46 & 11,9 \\
\hline não reduziu & reduziu & reduziu & 1 & 2,4 & 1 & 0,6 & 1 & 1,2 & 1 & 1,0 & 4 & 1,0 \\
\hline reduziu & não reduziu & não reduziu & & 0,0 & 4 & 2,5 & 2 & 2,4 & 1 & 1,0 & 7 & 1,8 \\
\hline reduziu & reduziu & reduziu & & 0,0 & & 0,0 & 1 & 1,2 & & 0,0 & 1 & 0,3 \\
\hline reduziu & não reduziu & não reduziu & 5 & 12,2 & 18 & 11,4 & 12 & 14,3 & 13 & 12,5 & 48 & 12,4 \\
\hline reduziu & reduziu & reduziu & 9 & 22,0 & 45 & 28,5 & 18 & 21,4 & 20 & 19,2 & 92 & 23,8 \\
\hline Total geral & & & 41 & 100,0 & 158 & 100,0 & 84 & 100,0 & 104 & 100,0 & 387 & 100,0 \\
\hline
\end{tabular}

Fonte: questionários, 2014, elaboração do autor.

Figura 6 - Proporção de famílias que reduziu o consumo (alimentação, vestuário/calçado e eletricidade/gás)

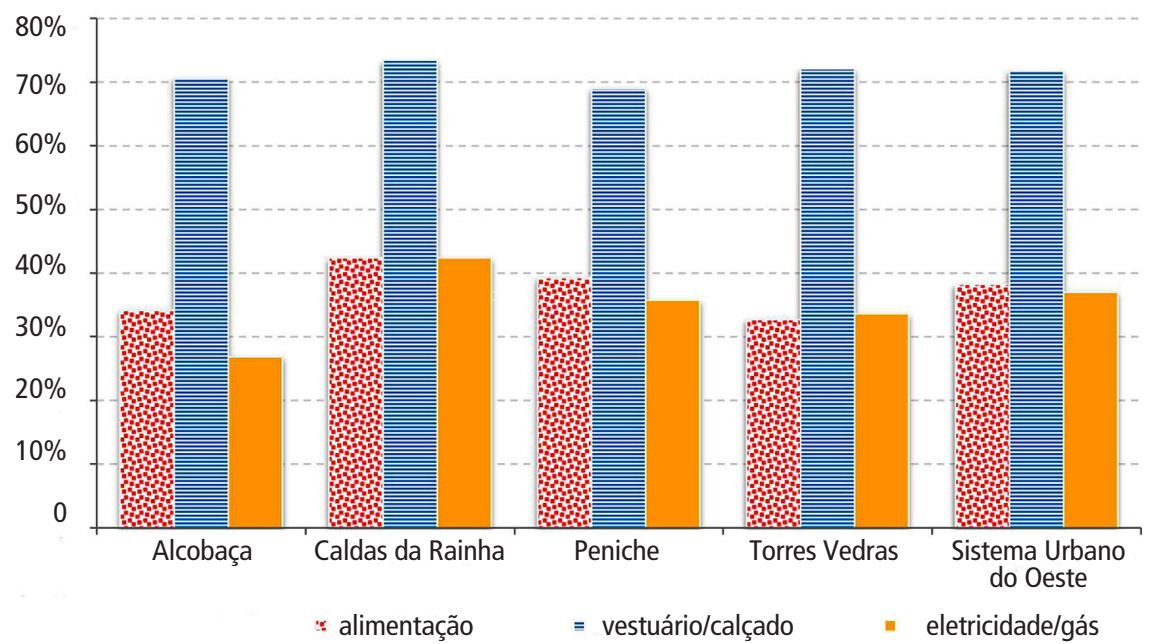

Fonte: questionários, 2014, elaboração do autor. 
É preciso dizer que $38 \%$ das famílias inquiridas, no contexto do sistema urbano, reportam cortes em alimentação (correspondendo a 42\% em Caldas da Rainha, 39\% em Peniche, $38 \%$ em Torres Vedras e 34\% em Alcobaça). Vestuário e calçado foram mais vezes alvos de cortes, acoplando, à resposta negativa, as expressões do gênero: "a alimentação é a última coisa a reduzir".

Os entrevistados que responderam afirmativamente nessa matéria ensaiaram várias fórmulas explicativas: desde a procura por produtos mais baratos (promoções, marcas brancas, pontos de venda mais econômicos), a exclusão de produtos mais caros (certos tipos de carne ou peixe, por exemplo), até a redução indiscriminada por total insuficiência econômica ou anulação de refeições (o jantar é, por vezes, suprimido ou reduzido). Nessa última situação, encontram-se as famílias que não dispõem de recursos para satisfazer esse tipo de necessidades.

Na contração do consumo de vestuário e calçado (no sistema urbano, $72 \%$ das famílias afirmam que cortaram nesse tipo de consumo, oscilando entre $71 \%$ e $73 \%$ quando se analisam as situações das 4 cidades individualmente), também se misturam várias realidades, que vão, desde a substituição dos locais de compra, até a aquisição de marcas mais baratas, a redução da frequência com que se fazem compras, passando pelo uso de roupas usadas cedidas por familiares ou amigos, até a total eliminação desse tipo de consumo.

As estratégias apresentadas para reduzir os custos da eletricidade e do gás (37\% das famílias no sistema urbano declararam ter reduzido esse tipo de consumo; em maior proporção nas Caldas da Rainha, 42\%; e menor em Alcobaça, 27\%) prendem-se com medidas de eliminação de desperdícios, embora seja frequente a referência ao fato de se tratar de um tipo de despesa que, pela sua natureza (em parte desligada da amplitude do consumo), não se molda facilmente a medidas de redução.

\section{Crise pós-2008 e aumento da exclusão social}

Serão tratados, agora, os mecanismos que as famílias primeiramente acionaram em situações de insuficiência econômica tendo em conta, nos seis anos considerados, o nível de exposição a situações de carências graves (dificuldade de suprir as despesas com alimentação, habitação e saúde) e, ainda, o grau de proximidade que as diferentes comunidades apresentam a situações similares. 0 corpo dessas linhas de análise organiza-se em diversas conclusões que, no conjunto, constroem um entendimento sobre a capacidade de redundância das comunidades e dos círculos familiares.

Quando solicitado aos entrevistados que indicasse a quem recorreriam caso se confrontassem com uma situação de insuficiência econômica (dificuldade de acesso à alimentação, habitação, saúde), foi recorrente a referência à família (Figura 7). Nesse panorama, existem nuances: no seu conjunto, as respostas indicam que, nas cidades do 0este, $62 \%$ das famílias recorreriam aos familiares em caso de impossibilidade de aceder aos bens essenciais considerados: alimentação, habitação e saúde (Figura 7). Essa realidade assume maior expressão em Peniche (74\%) e Torres Vedras $(63,5 \%)$ e menor em Caldas da Rainha (58\%) e Alcobaça (51\%). 
Figura 7- Instâncias/mecanismos a que as famílias recorreriam em situações de emergência econômica

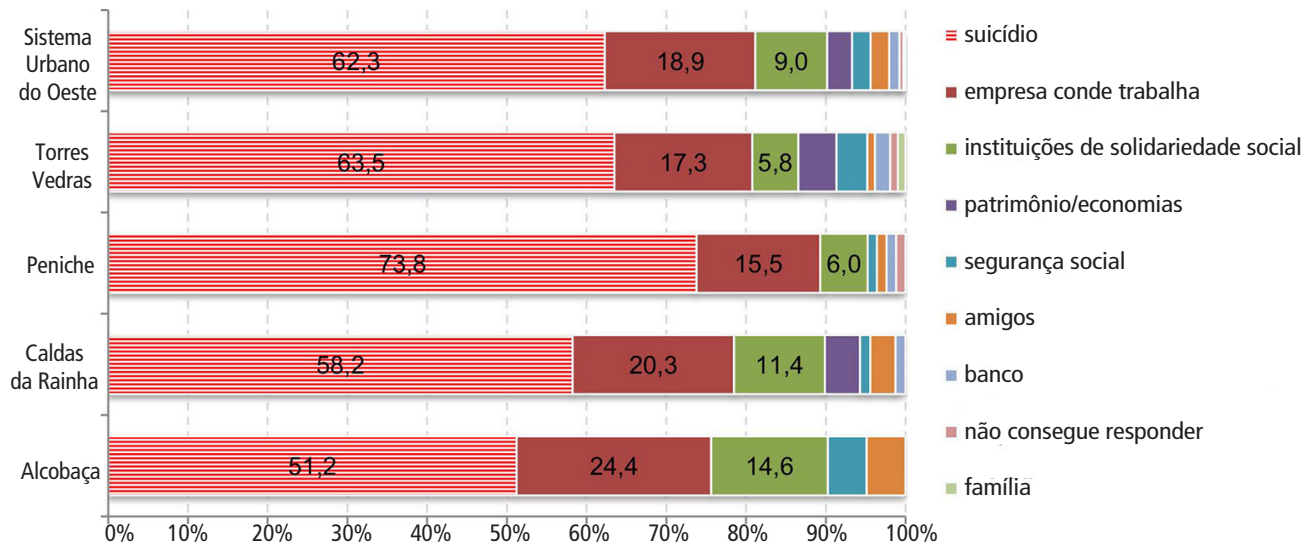

Fonte: questionários, 2014, elaboração do autor.

Por essa variável, pode-se vislumbrar a consistência dos laços familiares e de seu papel como estruturas de redundância por excelência e como elas respondem, precisamente, nos centros urbanos mais vulneráveis. Eis a primeira almofada para as situações mais graves. Em consequência, e com maior poder de esclarecimento, o peso das famílias que não conseguem responder à pergunta (inicialmente não havia essa classe, mas foi necessário introduzi-la), ou seja, quando confrontados com a interrogação, e após alguma consideração, a resposta formulada era (com variações todas confluentes para o mesmo sentido): "não consigo dizer a quem recorreria".

Nessa categoria estão contidas situações mais vulneráveis, ou porque mais distantes do "escudo" familiar, ou porque nenhuma das outras possibilidades surge com a consistência suficiente que permita ser formulada como resposta (por desconhecimento ou por indisponibilidade). Os resultados indicam que quase uma em cada cinco famílias revelou essa vulnerabilidade; valor semelhante verifica-se na cidade das Caldas da Rainha. A situação mais expressiva é a de Alcobaça (24\%), já as com menos gravidade são as de Torres Vedras (17\%) e de Peniche (15,5\%).

Em certa medida, são as instituições bancárias ou o patrimônio (imobiliário e não só) e as poupanças que substituem as relações familiares, nos casos em que estas são mais frágeis. Os amigos, para esse efeito, não assumem muita relevância. Mais residuais são as considerações em torno da segurança social ou das instituições de solidariedade social. São das últimas a serem consideradas.

Imediatamente a seguir a essa questão (feita, como se disse, num registro hipotético), colocava-se outra, de âmbito fechado e 
Tabela 6 - Famílias expostas a situações de carências econômicas graves

\begin{tabular}{|c|c|c|c|c|c|c|c|c|c|c|}
\hline & \multicolumn{2}{|c|}{ Alcobaça } & \multicolumn{2}{|c|}{$\begin{array}{l}\text { Caldas } \\
\text { da Rainha }\end{array}$} & \multicolumn{2}{|c|}{ Peniche } & \multicolumn{2}{|c|}{$\begin{array}{l}\text { Torres } \\
\text { Vedras }\end{array}$} & \multicolumn{2}{|c|}{$\begin{array}{c}\text { Sistema Urbano } \\
\text { do Oeste }\end{array}$} \\
\hline & fi & $f r$ & fi & $f r$ & fi & fr & fi & $f r$ & $f i$ & $f r$ \\
\hline Família & 7 & 53,8 & 41 & 61,2 & 30 & 85,7 & 29 & 80,6 & 107 & 70,9 \\
\hline Não consegue responder & 4 & 30,8 & 13 & 19,4 & 2 & 5,7 & - & 0,0 & 19 & 12,6 \\
\hline Banco & - & 0,0 & 7 & 10,4 & 1 & 2,9 & 1 & 2,8 & 9 & 6,0 \\
\hline Amigos & - & 0,0 & 3 & 4,5 & - & 0,0 & 2 & 5,6 & 5 & 3,3 \\
\hline Segurança social & 1 & 7,7 & - & 0,0 & 1 & 2,9 & 3 & 8,3 & 5 & 3,3 \\
\hline Patrimônio/economias & 1 & 7,7 & 2 & 3,0 & - & 0,0 & - & 0,0 & 3 & 2,0 \\
\hline Instituições de solidariedade social & - & 0,0 & 1 & 1,5 & 1 & 2,9 & 1 & 2,8 & 3 & 2,0 \\
\hline $\begin{array}{l}\text { Total de famílias que pediram ajuda } \\
\text { econômica nos últimos } 6 \text { anos }\end{array}$ & 13 & 100,0 & 67 & 100,0 & 35 & 100,0 & 36 & 100,0 & 151 & 100,0 \\
\hline Total geral & 41 & 31,7 & 158 & 42,4 & 84 & 41,7 & 104 & 34,6 & 387 & 39,0 \\
\hline
\end{tabular}

Fonte: questionários, 2014, elaboração do autor.

direto: perguntou-se se, nos seis anos considerados, a família do entrevistado passou por alguma situação dessa natureza (dificuldades de aceder à alimentação, habitação, saúde). As respostas a essa questão clarificaram quadros familiares de maior exclusão social numa ordem de grandeza que atinge $39 \%$ de famílias (pediu ajuda para suprir as despesas com alimentação, habitação e saúde) no período em causa, correspondendo a $38 \%$ da amostra ampliada (Tabela 6).

Do conjunto de famílias que tem como traço comum o fato de terem vivenciado ocasiões em que recorreram a ajuda econômica (151), os centros urbanos onde este quadro é mais recorrente são em Caldas da Rainha e Peniche (42\% das famílias passaram por esse constrangimento), a prevalência não é tão ampla em Torres Vedras (34,6\%) e em Alcobaça $(31,7 \%)$.

Abrindo o âmbito, para se ter uma visão sobre o grau de proximidade dos agregados familiares, na sua vivência quotidiana a esse tipo de situação, procurou-se saber se tinham contato direto (pessoal) com outros familiares, amigos, vizinhos ou colegas de trabalho que, fruto do contexto de crise, estivessem em situação de carências severas (bloqueios no acesso a alimentação, habitação, saúde). A sequência pretendeu estabelecer uma escala de mais próximo (outros familiares) ao mais afastado (colegas e trabalho), embora, neste último caso, tenha sido mantido o contato pessoal quotidiano (Tabela 7). 


\section{Tabela 7 - Nível de proximidade a situações de exclusão social provocadas pelo contexto de crise}

\begin{tabular}{|c|c|c|c|c|c|c|c|c|c|c|}
\hline & \multicolumn{2}{|c|}{ Alcobaça } & \multicolumn{2}{|c|}{$\begin{array}{c}\text { Caldas } \\
\text { da Rainha }\end{array}$} & \multicolumn{2}{|c|}{ Peniche } & \multicolumn{2}{|c|}{$\begin{array}{l}\text { Torres } \\
\text { Vedras }\end{array}$} & \multicolumn{2}{|c|}{$\begin{array}{c}\text { Sistema Urbano } \\
\text { do Oeste }\end{array}$} \\
\hline & $\mathrm{N}^{\circ}$ & $\%$ & $\mathrm{~N}^{\circ}$ & $\%$ & $\mathbf{N}^{\circ}$ & $\%$ & $\mathrm{~N}^{\circ}$ & $\%$ & $\mathbf{N}^{\circ}$ & $\%$ \\
\hline Familiares & 4 & 9,8 & 21 & 13,3 & 9 & 10,7 & 9 & 8,7 & 43 & 11,1 \\
\hline Familiares + amigos & - & - & 3 & 1,9 & 4 & 4,8 & 1 & 1,0 & 8 & 2,1 \\
\hline Familiares + amigos + vizinhos & - & - & - & - & 1 & 1,2 & - & - & 1 & 0,3 \\
\hline $\begin{array}{l}\text { Familiares }+ \text { amigos }+ \text { vizinhos }+ \\
\text { colegas de trabalho }\end{array}$ & - & - & - & - & - & - & 1 & 1,0 & 1 & 0,3 \\
\hline Familiares + colegas de trabalho & - & - & 1 & 0,6 & - & 0,0 & - & - & 1 & 0,3 \\
\hline Amigos & 2 & 4,9 & 23 & 14,6 & 10 & 11,9 & 10 & 9,6 & 45 & 11,6 \\
\hline Amigos + colegas de trabalho & - & - & 1 & 0,6 & - & - & - & & 1 & 0,3 \\
\hline Amigos + vizinhos & - & - & 1 & 0,6 & - & - & 1 & 1,0 & 2 & 0,5 \\
\hline $\begin{array}{l}\text { Amigos + vizinhos + colegas de } \\
\text { trabalho }\end{array}$ & - & - & 1 & 0,6 & - & - & - & - & 1 & 0,3 \\
\hline Vizinhos & 3 & 7,3 & 12 & 7,6 & 7 & 8,3 & 15 & 14,4 & 37 & 9,6 \\
\hline Vizinhos + colegas de trabalho & - & - & - & - & 1 & 1,2 & - & - & 1 & 0,3 \\
\hline Colegas de trabalho & - & - & 11 & 7,0 & 7 & 8,3 & 11 & 10,6 & 29 & 7,5 \\
\hline Sem contato & 32 & 78,0 & 84 & 53,2 & 45 & 53,6 & 56 & 53,8 & 217 & 56,1 \\
\hline Total geral & 41 & 100 & 158 & 100 & 84 & 100 & 104 & 100 & 387 & 100 \\
\hline
\end{tabular}

Fonte: questionários, 2014, elaboração do autor.

Resulta, desse exercício, o indicador de que $44 \%$ das famílias contatavam direta e quotidianamente famílias com dificuldades de suprir suas necessidades básicas. Essa realidade é vivida por cerca de $47 \%$ da amostra de famílias entrevistadas nas Caldas da Rainha, Peniche e Torres Vedras. Alcobaça não apresenta tanta proeminência dessa realidade (22\%). As justificativas para os que respondem negativamente a essa solicitação são ensaiadas no discurso: de que se ouve dizer que existe, mas as pessoas escondem, que, mais recorrente em Alcobaça, a ligação à terra acaba por camuflar a gravidade desse tipo de carência; em "meios pequenos", dizem, "as pessoas desenrascam-se e disfarçam melhor".

Do outro lado, da parte dos entrevistados que experienciam mais de perto situações de carências, abundam as exposições mais impressivas.

A prevalência dos casos de carências básicas somada aos casos que restringiram bastante suas aquisições, mantendo-se no âmbito da privação material, ganha maior amplitude quando se analisa o grau de proximidade que a comunidade manifesta em face desses quadros de maior exclusão social. Paira, em muitos desses casos, uma penumbra de desistência e 
de depressão, mas evidencia-se uma banda de amortecimento silencioso que impede que se assista a surtos de indigência. Mas, os resultados demonstram um processo de bloqueio, difícil de desmantelar, no desenvolvimento dessas comunidades.

\section{Considerações finais}

A crise pós-2008 provocou profundas transformações globais. 0 mercado de trabalho foi sem dúvida uma das áreas em que os efeitos foram mais severos no contexto europeu. Todavia, os países do Sul da Europa, nos quais mais se fizeram sentir as politicas de austeridade, fizeram com que a contração do emprego e dos rendimentos a ele associados amplificassem as situações de exclusão social.

Vão, nesse sentido, as conclusões que se obtiveram na análise das cidades portuguesas tomadas como estudo. A proliferação de níveis de rendimentos muito baixos (46\% das famílias não dispõem de mais que 437 euros mensais per capita) condiciona a qualidade de vida e arrasta as famílias para condições de vulnerabilidade que Ihes cortam a possibilidade de contribuir para o progresso da comunidade. Muitas famílias, pela redução que sofreram nos rendimentos mensais (65\% perdeu pelo menos 1/4 do seu ganho mensal), foram arrastadas para essa situação nos anos pós-2008.

Acrescenta-se, ao ponto anterior, o fato de mais da metade das famílias antever possibilidades de degradação no seu quadro de fontes de rendimento ( $57 \%$ considera os seus rendimentos familiares instáveis ou muito instáveis). Assim, degradam-se as condições para qualificar a vida familiar e o contexto social (nas suas múltiplas dimensões).

0 fato de para cada 100 inativos existir apenas 75 dos ativos é um estrangulamento severo à capacidade de mobilizar esforço de desenvolvimento, resultando num duplo constrangimento: por um lado, avoluma a parte do esforço que recai sobre os ativos em minoria; por outro (e se tivermos em conta que os inativos são, sobretudo, desempregados (31\%) e reformados ou pensionistas (correspondem a $37,4 \%$ dos ativos empregados), a fragilidade da fatia que pode suportar ou introduzir transformações na estrutura econômica é elevada. Eis uma tarraxa bem apertada em torno do potencial de desenvolvimento.

A proporção de desempregados colocados à margem de qualquer fonte de rendimento $(41 \%$, não recebe subsidio de desemprego) desgasta uma parte significativa da população ativa, encostando-a a contextos de grande marginalidade, que a afastam gradualmente da sociedade, dispensando-se, assim, o seu potencial. No cenário mais benevolente, a prazo, desperdiçam-se/comprometem-se recursos. Cola-se aos aspetos anteriores, amplificando-os, o fato de boa parte dos desempregados (45\%) terem mais de 45 anos, expondo-os a maiores fragilidades em face de um quadro de proteção social e de um mercado de trabalho que os exclui.

Se é certo que se poderá dizer que parte desse desemprego (34\% é a proporção de desempregados em relação aos ativos) é pontual ou que remete causas para uma conjuntura de tempo mais lato, tal perde aderência quando se percebe que 40,5\% das famílias, nos últimos 6 anos, tiveram pelo menos 1 dos seus elementos em situações de desemprego (muitos casos 
mais do que 1 elemento) e que, quando retomaram o mercado de trabalho, o rendimento que auferiam se manteve ou regrediu (apenas 13,4\% nessas circunstâncias aumentaram o ordenado quando retomaram ao mercado de trabalho, 17,4\% não voltaram). É um problema generalizado, que afeta uma parte significativa da comunidade, degradando a sua capacidade de aceder a fontes de rendimentos, erodindo a sua capacidade de progredir;

Essas situações de carências traduzem-se na quantidade de famílias que tiveram de cortar na alimentação (38\%) e nas $24 \%$ que conheceram constrangimentos na aquisição dos três bens essenciais (alimentação, vestuário e calçado, eletricidade e gás). No fim dessa linha, surgem as famílias (39\%) que tiveram de pedir ajuda para, durante o período em análise, ultrapassar situações em que não conseguiam satisfazer necessidades básicas (alimentação, habitação, saúde) sinalizando contextos de risco de exclusão muito elevados, correspondendo a situações em que as famílias não dispuseram de recursos para se alimentarem, para pagar as despesas com a habitação e com saúde. Ou seja: enfrentaram riscos de fome, de serem desalojados e não poderem tratar da sua saúde. Esse quadro de fortes impactos da crise generaliza-se quando se percebe que a convivência quotidiana com situações de risco de exclusão dessa natureza assume uma expressão significativa (44\% dos entrevistados convivem diariamente com essas carências: nas famílias, nos amigos ou nos colegas de trabalho).

Os seis anos analisados permitem perceber que a crise assume proporções mais profundas, quando a avaliação é mais detalhada e a escala mais aproximada, aspectos quase sempre descorados nos relatórios das instituições mundiais, europeias e nacionais. Nas cidades estudadas, tendo em conta a primeira fase da crise (2008-2014), assistiu-se à desestruturação das suas estruturas de emprego, conduzindo a uma forte contração nos rendimentos, que por sua vez aumentou as situações de risco de exclusão social.

\section{Carlos Gonçalves}

Universidade de Lisboa, Instituto de Geografia e Ordenamento do Território, Centro de Estudos Geográficos. Lisboa, Portugal.

c.goncalves@campus.ul.pt 


\section{Notas}

(1) NUTs é o acrônimo de "Nomenclatura das Unidades Territoriais para Fins Estatísticos", sistema hierárquico de divisão do território em regiões. Essa nomenclatura foi criada pelo Eurostat no início dos anos 1970, visando à harmonização das estatísticas dos vários países em termos de recolha, compilação e divulgação de estatísticas regionais. Portugal desagrupa-se em 3 NUTs de nível I, 7 de nível II e 25 de nível III. Assim, a NUT III Oeste é uma das 8 subunidades territóriais integradas na NUT II Centro. A NUT II Centro corresponde a uma das 7 que se agrupam na NUT I Continente.

(2) NUTs is the acronym for "Nomenclature of Territorial Units for Statistical Purposes", a hierarchical system of division of territory into regions.

(3) À semelhança do que sucedeu no final dos anos 1920, quando o reforço do liberalismo conduziu ou colapso do mercado acionista em 1929 ou quando, em meados dos anos 1970, a matriz de regulação do capitalismo implantado no final da Segunda Guerra Mundial foi abandonada.

(4) A cidade de Torres Vedras tinha 7.095 famílias residentes em 2011, Peniche tinha 6.070, Caldas da Rainha 11.552 e Alcobaça 3.009. Tendo em conta uma população (nesse caso, o total das famílias

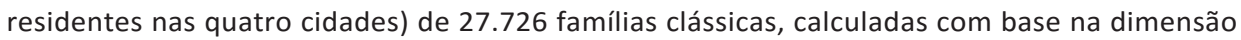
média, obteve-se a indicação de que, tendo em vista uma margem de erro máxima associada à amostra de $5 \%$, com um nível de confiança de $95 \%$, a dimensão da amostra corresponderia a 380 questionários.

(5) Ensino Fundamental I, no caso do Brasil.

(6) Este trabalho insere-se numa análise mais extensa da informação recolhida que pode ser consultada em (Gonçalves, 2014). De igual modo, neste documento, pode-se consultar uma caraterização detalhada da amostra.

(7) Conversão feita tendo em conta os valores do dia 5/1/2017.

(8) Esse valor posiciona-se entre o limiar do risco de pobreza (409 uros em 2012), o respeitante ao indexante de apoios sociais (419 euros) e o valor do salário mínimo nacional (485 euros). Para melhor enquadrar a especificidade desses resultados, é conveniente ter em mente dois conceitos definidos da seguinte forma pelo INE: Linha de pobreza: "limiar do rendimento abaixo do qual se considera que uma família se encontra em risco de pobreza. Esse valor foi convencionado pela Comissão Europeia como sendo o correspondente a $60 \%$ da mediana do rendimento por adulto equivalente de cada país". População em risco de pobreza ou exclusão social: "indivíduos em risco de pobreza ou vivendo em agregados com intensidade laboral per capita muito reduzida ou em situação de privação material severa". Informação disponível em: http://smi.ine.pt/.

(9) O subsídio de desemprego é uma prestação em dinheiro atribuída aos beneficiários desempregados para compensar a falta de remuneração motivada pela perda involuntária de emprego. Para ter direito a essa prestação social, é necessário reunir as seguintes condições: residir em Portugal; estar em situação de desemprego involuntário; ter capacidade e disponibilidade para o trabalho; estar inscrito para procura de emprego no centro de emprego da área de residência; e ter o prazo de garantia exigido que corresponde a 360 dias de trabalho por conta de outrem com registo de remunerações nos 24 meses anteriores à data do desemprego. $O$ valor a receber corresponde a $65 \%$ do montante diário da remuneração de referência, calculado na base de 30 dias por mês. 
(10) O Rendimento Social de Inserção (RSI) é uma medida de proteção social criada para apoiar pessoas ou famílias que se encontrem em situação de grave carência econômica e em risco de exclusão social, e é constituída por: um contrato de inserção para os ajudar a integrar-se social e profissionalmente; e uma prestação em dinheiro para satisfação das suas necessidades básicas. As pessoas, para receberem o Rendimento Social de Inserção, celebram e assinam um Contrato de Inserção, do qual consta um conjunto de deveres e direitos, com vista à sua integração social e profissional. Reúnem condições para beneficiar do RSI as pessoas que vivem sozinhas ou famílias cuja soma dos seus rendimentos mensais seja inferior a 183,84 euros (622 reais). No caso das famílias, a soma dos rendimentos mensais de todos os elementos do agregado familiar não pode ser igual ou superior ao valor máximo de RSI, calculado em função da composição do agregado familiar (pelo titular: 183,84 euros, $100 \%$ do valor do RSI; por cada indivíduo maior: 128,69 euros, $70 \%$ do valor do RSI; por cada indivíduo menor 91,92 euros , $50 \%$ do valor do RSI).

(11) Os dados divulgados pelo IEFP correspondem ao "desemprego registado", que mede a expressão administrativa dos indivíduos que se inscrevem nos Centros de Emprego, sendo posteriormente classificados como desempregados, após determinados procedimentos. Sendo classificadas como "desempregadas" as pessoas com idade mínima de 16 anos (com exceção dos casos previstos na lei), inscritas nos Centros de Emprego, que não têm um trabalho e que estejam disponíveis para trabalhar e que procuram um emprego por conta de outrem. Informaçõe disponíveis em: http://www.ine.pt/.

\section{Referências}

ATKINSON, R., e DAVUDI, S. (2000). The concept of social exclusion in the European Union. Journal of Comon Market Studies, v. 38, n. 3, pp. 427-448.

COMMISSION, EUROPEAN, DIRECTORATE-GENERAL FOR EMPLOYMENT (2015). Employment and social developments in Europe 2015 (vol. 1).

CUADRADO-ROURA; J. R., MARTIN, R. e RODRÍGUEZ-POSE, A. (2016). The economic crisis in Europe: urban and regional consequences. Cambridge Journal of Regions, Economy and Society, v. 9, n. 1, pp. 3-11.

CUTTER, S.; BORUFF, B. e SHIRLEY, L. (2003). Social Vulnerability to Environmental Hazards. Social Science Quarterly, v. 84, n. 2, pp. 242-260.

ECOTRUST (2012). Resilience \& Transformation a regional approach. Portland.

ERAYDIN, A. (2013). "Resilience Thinking for Planning". In: ERAYDIN, A. e TASAN-KOK, T. (orgs.). Resilience Thinking in Urban Planning, v. 106, pp. 17-38. Dordrecht, Springer Netherlands. Disponível em: http://doi.org/10.1007/978-94-007-5476-8. Acesso em: 7 jun 2013.

EUROFOUND. (2016). Families in the economic crisis: Changes in policy measures in the EU. Luxembourg, Publications Office of the European Union. Disponivel em: http://doi.org/10.2806/208757. Acesso em: 3 mar 2016.

ESPON. (2013). Economic crisis: resilience of regions. Revised Interim Report. Luxemburgo. 
EUROPEAN COMMISSION. (2011). Regional Challenges in the Perspective of 2020 - Phase 2: Deepening and Broadening the Analysis. Vienna/Heisdorf/Bonn.

EUROPEAN COMMISSION DIRECTORATE-GENERAL FOR ECONOMIC AND FINANCIAL AFFAIRS (2009). Economic crisis in Europe: causes, consequences and responses. Luxemburgo.

EUROPEAN COMMISSION, DIRECTORATE-GENERAL FOR EMPLOYMENt (2009). Employment in Europe 2009.

FRATESI, U. e RODRÍGUEZ-POSE, A. (2016). The crisis and regional employment in Europe: What role for sheltered economies? Cambridge Journal of Regions, Economy and Society, v. 9, n. 1, pp. 33-57.

FUJITA, K. (2013). Introduction : cities and crisis: new critical urban theory. Sage,

GARRETSEN, H.; MCCANN, P.; MARTIN, R. e TYLER, P. (2013). The future of regional policy. Cambridge Journal of Regions, Economy and Society, v. 6, n. 2, pp. 179-186.

GONÇALVES, C. (2014). Resiliência, sustentabilidade e qualidade de vida em sistemas urbanos: efeitos da crise (pós-2008) em Portugal e no sistema urbano do Oeste. Tese de Doutorado. Lisboa, Universidade de Lisboa.

HADJIMICHALIS, C. (2011). Uneven geographical development and socio-spatial justice and solidarity: European regions after the 2009 financial crisis. European Urban and Regional Studies, v. 18, n. 3, pp. 254-274.

HOMER-DIXON, T. et al. (2015). Synchronous failure: The emerging causal architecture of global crisis. Ecology and Society, v. 20, n. 3.

KOTZ, D. M. (2009). The financial and economic crisis of 2008: a systemic crisis of neoliberal capitalism. Review of Radical Political Economics, v. 41, n. 3, pp. 305-317.

MADANIPOUR, A.; SHUCKSMITH, M. e TALBOT, H. (2015). Concepts of poverty and social exclusion in Europe. Local Economy, v. 30, n. 7, pp. 721-741. Disponível em http://doi. org/10.1177/0269094215601634. Acesso em: 6 jan 2015.

MARELLI, E.; PATUELLI, R. e SIGNORELLI, M. (2012). Regional unemployment in the EU before and after the global crisis. Post Communist Economies, v. 24, n. 2, pp. 155-175. Disponível em: http://doi. org/10.1080/14631377.2012.675153. Acesso em: 27 ago 2016.

MILLER, F. et al. (2010). Resilience and vulnerability: complementary or conflicting concepts? Ecology and Society, v. 15, n. 3.

NAUDÉ, W.; MCGILLIVRAY, M. e ROSSOUW, S. (2009). Measuring the Vulnerability of Subnational Regions in South Africa. Oxford Development Studies, v. 37, n. 3, pp. 249-276. Disponível em: http://doi.org/10.1080/13600810903085800. Acesso em: 14 dez 2013.

O'BRIEN, M. e PENNA, S. (2008). Social exclusion in Europe: some conceptual issues. International Journal of Social Welfare, v. 17, n. 1, pp. 84-92. Disponível em: http://doi.org/10.1111/j.14682397.2006.00478.x. Acesso em: 6 jan 2016.

RACO, M. e STREET, E. (2012). Resilience Planning, Economic Change and in London and Hong Kong. Urban Studies, v. 49, n. 5, pp. 1065-1087.

REDE EUROPEIA ANTI-POBREZA (2014). Indicadores sobre a pobreza Dados Europeus e Nacionais. Atualização março 2014. Porto. 
SEELIGER, L. e TUROK, I. (2013). Towards sustainable cities: extending resilience with insights from vulnerability and transition theory. Sustainability, v. 5, n. 5, pp. 2108-2128. Disponível em: http:// doi.org/10.3390/su5052108. Acesso em: 10 jul 2014.

SILVEY, R. (2010). Development geography: politics and "the state" under crisis. Progress in Human Geography, v. 34, n. 6, pp. 828-834.

TOSUN, J.; WETZEL, A. e ZAPRYANOVA, G. (2014). The EU in crisis: advancing the debate. Journal of European Integration, v. 36, n. 3, pp. 195-211.

URBACT (2010). Urbact cities facing the crisis responses. França, Saint-Denis La Plaine.

Texto recebido em 30/ago/2016

Texto aprovado em 8/dez/2016 